\title{
The Inefficiency of Short-Run Monetary Targets for Monetary Policy
}

THE ADOPTION of short-run monetary targets has been the most significant development in the practice of central banking during the 1970s, at least in the context of domestic monetary policy. The central banks of most of the industrialized Western economies now use explicit targets for monetary growth in formulating and implementing monetary policy. In the United States the Federal Reserve System moved informally to a greater emphasis on the monetary aggregates in early 1970; and since 1975 the Congress, under House Concurrent Resolution 133, has required the Chairman of the Federal Reserve Board to report formally each quarter the specific monetary-growth targets chosen by the Federal Open Market Committee as the near-term objective of monetary policy. Private economic analysts in turn have come to focus on such announcements, and comparing each Thursday's new money statistics against the corresponding target values is now the economic highlight of the week in the financial markets. In short, the era of monetary policy by monetary targets has arrived.

For the most part, both academic economists and the business community have welcomed this development. During the mid-1960s a number

Note: I am grateful to David Jones for research assistance; to Michael Bruno, Richard G. Davis, John Flemming, Michael Hamburger, and David Jones, as well as to the editors, my discussants, and other members of the Brookings panel, for helpful comments on an earlier draft of the paper; and to the National Bureau of Economic Research for research support. 
of researchers had pointed out logical flaws in the Federal Reserve's operating strategy of orienting monetary policy so as to maintain the banking system's net free-reserve position, and the acceleration of price inflation later in the decade brought out the ambiguities in the subsequent strategy of setting policy according to observed (nominal) short-term interest rates. As inflation persisted and, indeed, accelerated in the 1970s, the relevance to monetary policy of the long-run relationship between money and prices became clear. In addition, many who had criticized federal budget deficits and had also observed the tendency of monetary growth to be greatest at times of substantial deficit spending welcomed the "discipline" that resistance to monetary expansion imposed on the federal budget. If the old "Treasury view" that the financing requirements associated with budget deficits rendered fiscal policy impotent was not valid independently, then adherence to unchanging monetary-growth targets helped to make it so. The adoption of monetary-growth targets as the focus of monetary policy therefore accomplished several purposes and thus has attracted support from diverse constituencies.

Nevertheless, after the initial burst of enthusiasm, it is appropriate to scrutinize the use of monetary-growth targets, and to determine whether or not this approach meets the requirements of sound policymaking. This paper asks, in other words, whether the monetary-target strategy serves the intended purposes of monetary policy about as well as other plausible structures. Alternatively, is it possible, within the limitations imposed by the current state of economic knowledge, either to devise a different but superior approach to monetary policymaking or to suggest sensible ways of adapting and improving the monetary-target approach itself?

Two caveats regarding the paper's perspective should be stated at the outset.

First, whether the paper's central message constitutes a tribute to or an indictment of current U.S. monetary policy depends ultimately on a judgment of what the Federal Reserve System really does. One can argue, for example, that no reasonable central banker would in practice formulate and implement monetary policy according to the monetary-target approach as described in this paper. The counter to this objection is that, while no one book-let alone one paper-can encompass all of the subtleties of the art of central banking, the characterization of the monetary-target strategy analyzed here is to a first approximation a faithful if capsulized representation of the procedure now widely supported in its 
major outlines-including by the Congress under Resolution 133. To what extent the Federal Open Market Committee in fact currently follows this procedure is a positive empirical question that lies beyond the scope of this paper, but the paper's normative conclusions are relevant to future decisions about monetary policy regardless of what has happened in the past. ${ }^{1}$

Second, this paper accepts at face value the proposition that central bankers are competent men and women who take decisions to advance the public weal, guided both by the intent of Congress and by their own values and intelligence. The analyst who starts from the premise that the policymaker is either a fool or a scoundrel will inevitably find superior whatever policymaking framework imposes the tightest straitjacket and thereby ensures the maximum protection against malfeasance due to ignorance or rascality. ${ }^{2}$ By contrast, the central question of this paper is how best to enable the central bank to pursue those ultimate objectives that it deems appropriate. ${ }^{3}$

The first two sections of the paper analyze, at the conceptual level, the use of monetary targets as the focus of short-run monetary policy. The first section briefly reviews some pertinent aspects of the history of the adoption of monetary-growth targets, as well as some familiar aspects of the theory of monetary policy. The next section begins by defining the "intermediate target" policy approach. In particular, the discussion here uses several examples to emphasize that the key rationale underlying the intermediate-target approach-whether the intermediate target is the money stock or any other variable-is the existence of some asymmetry in the flow of scarce information in an uncertain world. This section then goes on to analyze two principal drawbacks of the intermediate-target approach as implemented by the Federal Reserve: The first is the exclusion,

1. Some critics of recent U.S. monetary policy have alleged that the Federal Reserve's purported emphasis on monetary-growth targets is largely rhetorical, and that the concern to stabilize short-run fluctuations in short-term interest rates has precluded monetary control in any real sense. For evidence to the contrary, however, see Paul DeRosa and Gary H. Stern, "Monetary Control and the Federal Funds Rate," Journal of Monetary Economics, vol. 3 (April 1977), pp. 217-30.

2. The ignorance that matters in this context is not simple ignorance about how the economy works but, instead, ignorance about how much is known of the economy's workings.

3. The legal status of the central bank in the United States makes clear that it is the Federal Reserve's responsibility to pursue whatever ultimate targets for economic performance the Congress indicates. 
as a result of the partially mistaken emphasis on the "controllability" of the intermediate target, of potentially valuable information that bears on appropriate policy actions but arises from sources other than observations of the money stock. The second is the incorrect incorporation, except under very restrictive assumptions, of even the limited information that the intermediate-target approach does use.

The third section evaluates empirically the way in which the intermediate-target approach based on the money stock as the intermediate target variable incorrectly incorporates the information contained in observations of the money stock. To gain an idea of the relevant magnitudes involved in the preceding analytical discussion, the paper develops and estimates, using U.S. data, a simple "bare essentials" macroeconometric model consisting of only five behavioral equations: real spending (the "IS" curve), price setting, money demand (the "LM" curve), money supply, and the term structure of interest rates. Apart from the separation of the determination of real income and prices, which is unusual in a small empirical macro model, this model has several interesting featuresincluding open-economy effects on both real income and prices, effects of debt-management policy on the term structure, and evidence that bank-portfolio behavior underlying the money-supply process differs from that assumed by familiar models. Here again, however, a word of caution is in order. The paper does not offer this small model as the best state-of-the-art representation of knowledge of the U.S. economy, nor does it attempt to use the model to derive specific monetary-policy rules to recommend to the Federal Open Market Committee. Instead, the objective is simply to illustrate the gross orders of magnitude of several interesting aspects of the monetary-policy process based on the monetarytarget approach. For purposes of such illustration, compactness and analytical tractability take precedence over elaborate specification searches, complex lag structures, and comprehensive lists of supposedly exogenous variables.

A final section summarizes the paper's principal findings and states their implications for the conduct of monetary policy.

\section{Historical Background and Analytical First Principles}

It is an historical curiosity that open market operations (that is, the purchase and sale of securities directly for the account of the Federal 
Reserve System), which today constitute the most important tool of monetary policy, were not even contemplated as such in the 1913 Federal Reserve Act. Consequently, the strategy and tactics for exercising this means of economic control evolved only after the realization in the $1920 \mathrm{~s}$ of how and why it worked. The establishment of the Federal Open Market Committee led temporarily to an increasing reliance on open market operations, ${ }^{4}$ but monetary policy turned in other directions after the depression set in; and thereafter the Federal Reserve's wartime commitment to support the prices of Treasury debt issues precluded an active policy. Only after 1951, when the Treasury-Federal Reserve Accord relieved the central bank of this obligation, did the use of open market operations for macroeconomic policy purposes finally come into its own.

\section{THE ADVENT OF MONETARY-GROWTH TARGETS}

During the first years after the accord, the Open Market Committee focused monetary policy on controlling the net free reserves (excess reserves less borrowed reserves) of the commercial banking system, adhering to a theory of open market operations based on the sources and uses of member-bank reserves developed by Winfield Riefler and Randolph Burgess. ${ }^{5}$ On the twin assumptions of interest-inelastic demand for excess reserves and reluctance to borrow at the discount window, net free reserves measured banks' willingness to extend loans and create deposits, and hence measured the effect of monetary policy in stimulating or retarding nonfinancial economic activity. In addition, net free reserves appeared to constitute the perfect "money market" variable-a close proxy for interest rates, yet not itself an interest rate and hence not a contradiction of the accord.

Within a decade, however, economists raised telling objections to the free-reserves strategy. Karl Brunner and Allan Meltzer, in a report prepared for a fiftieth anniversary review of the Federal Reserve System

4. It was originally called the Open Market Investment Committee, was renamed the Open Market Policy Conference in 1930, and given its current name in the mid1930s. For related historical background, see Milton Friedman and Anna J. Schwartz, A Monetary History of the United States, 1867-1960 (Princeton University Press for the National Bureau of Economic Research, 1963), especially chap. 6.

5. Winfield W. Riefler, Money Rates and Money Markets in the United States (Harper, 1930); and W. Randolph Burgess, The Reserve Banks and the Money Market (Harper, 1927). 
in $1964,{ }^{6}$ strongly criticized the use of free reserves as an "indicator" of the effect of monetary policy. At about the same time James Meigs and others showed that, since the demands by banks for both borrowed reserves and excess reserves were interest elastic, the banking system's desired free reserves depended on the discount rate and on market yields; ${ }^{7}$ hence what mattered, from the standpoint of both money (or credit) creation and the impact on economic activity, was not observed free reserves but the difference between them and desired free reserves. ${ }^{8}$

When the debates of the mid-1960s exposed the flaws in the freereserves strategy, the Open Market Committee adopted the strategy of setting some short-term interest rate (first the Treasury bill rate, and later the federal funds rate). Apart from any slippage in the term structure of interest rates, this strategy represented in the first instance an effort to concentrate on the influence of monetary policy on economic activity via the relationships summarized in the Hicksian IS curve. In addition, after 1965, Regulation Q, which imposed ceilings on deposit interest rates, rendered short-term market interest rates important in another way, given the peculiar institutional features of the U.S. mortgage market and the associated cyclical role of homebuilding.

Several related strands of criticism, however, all advanced the conclusion that the strategy based on market interest rates suffered from essentially the same drawback that defeated the free-reserves strategy. In particular, it was not appropriate to regard monetary policy as steady (or changing) just because market interest rates were fixed (or moving); instead, what mattered was the relationship between observed interest rates and something else-something that was at best difficult to determine. One facet of the development of this argument was the debate that

6. Karl Brunner and Allan H. Meltzer, The Federal Reserve's Attachment to the Free Reserve Concept, Prepared for the Subcommittee on Domestic Finance of the House Committee on Banking and Currency, 88:2 (Government Printing Office, 1964).

7. A. James Meigs, Free Reserves and the Money Supply (University of Chicago Press, 1962).

8. Especially in the context of this paper's focus on monetary targets, it is useful to distinguish two aspects of the 1960s criticism of the free-reserves mechanism: first, that the banking system's observed free-reserves position was a poor indicator of the effect of monetary policy on nonfinancial economic activity; and, second, that the free-reserves position was a poor instrument for controlling the money stock. The latter criticism was somewhat beside the point, since the Federal Reserve at that time placed little emphasis on the money stock and did not construe free reserves as a means of controlling it. 
ensued from the submission by Milton Friedman and David Meiselman to the Commission on Money and Credit, attempting to show empirically that the IS curve (or "multiplier relation") which the interest-rate strategy exploited was less reliable (that is, less stable) than the moneyincome relation, or Hicksian LM curve. ${ }^{9}$ At the conceptual level, William Poole showed, in the context of a simplified stochastic model, the conditions under which a strategy for monetary policy based on interest rates and exploiting the IS curve was preferable to one based on the money stock and exploiting the LM curve. ${ }^{10}$ Events played a part, too, as the acceleration and increasing volatility of price inflation rendered the inference of a "real" market rate of interest ever more difficult. To the extent that allowing for price expectations is basic to interpreting observed (nominal) interest rates as "indicators" of the likely effect of monetary policy on nonfinancial economic activity, calculating such corrections had become extremely complicated by 1970; and the merits of the strategy based on money-growth targets, advocated most notably by Milton Friedman, seemed both more obvious and more relevant. ${ }^{11}$

After some unsuccessful experimentation in the late 1960s with a "proviso" approach, according to which the Manager of the Open Market Account pursued a stated interest-rate objective provided that doing so did not cause an aggregate measure to deviate from a predetermined range, in 1970 the Open Market Committee adopted an operating strategy

9. Milton Friedman and David Meiselman, "The Relative Stability of Monetary Velocity and the Investment Multiplier in the United States, 1897-1958," in Stabilization Policies, Prepared for the Commission on Money and Credit (Prentice-Hall, 1963), pp. 165-268. Several years later the work of Andersen and Jordan and others at the Federal Reserve Bank of St. Louis returned, in a somewhat different context, to the stability of the money-income relation; see Leonall C. Andersen and Jerry L. Jordan, "Monetary and Fiscal Actions: A Test of Their Relative Importance in Economic Stabilization," Federal Reserve Bank of St. Louis, Review, vol. 50 (November 1968), pp. 11-24.

10. William Poole, "Optimal Choice of Monetary Policy Instruments in a Simple Stochastic Macro Model,” Quarterly Journal of Economics, vol. 84 (May 1970), pp. 197-216.

11. Milton Friedman, A Program for Monetary Stability (Fordham University Press, 1959); Friedman, "The Role of Monetary Policy," American Economic Review, vol. 58 (March 1968), pp. 1-17. For an interesting account of the increased appeal of monetarist approaches, to theory as well as policy, during inflationary times, see Harry G. Johnson, "The Keynesian Revolution and the Monetarist CounterRevolution," American Economic Review, vol. 61 (May 1971), pp. 1-14, 
based on monetary-growth targets (or "monetary aggregates"). ${ }^{12}$ Directives to the manager continued to specify a narrowly constrained federal funds rate, but with a clear understanding that this practice was in large part meant to achieve a desired (or "targeted") rate of growth of the monetary aggregates.

The Open Market Committee's new approach to monetary policy has subsequently evolved into a well-defined two-stage procedure. ${ }^{13}$ First, at the "strategy" level, once per quarter the committee translates its ultimate policy aims (in terms of the economy's growth, employment, price stability, and so on) into a set of desired growth rates for the monetary aggregates over the next year. Because it will choose a new set of desired one-year growth rates three months later, however, only the first quarter of this one-year extrapolation is of direct operational relevance. Second, at the "tactics" level, within the quarter the committee determines how best to manipulate the instruments over which it can exert close control (such as nonborrowed bank reserves, or a short-term interest rate) so as to cause the designated monetary aggregates to move in the specified way; in practice the committee has typically used the federal funds rate in this instrument role. Although the committee meets formally only once a month, it occasionally uses telephone conferences to make additional within-quarter adjustments in the setting of the funds rate aimed at achieving the desired monetary growth, subject only to the need to avoid undue instability in the money market. ${ }^{14}$ In addition, the committee's specified

12. The aggregate most typically used in the "proviso clause," however, was not a money-stock measure but rather either the "bank credit proxy"-total bank credit as implicitly measured by an adjustment to total bank liabilities-or member-bank reserves.

13. Several Federal Reserve economists have provided useful descriptions of the workings of U.S. monetary policy under the monetary-growth-target approach. See, for example, Richard G. Davis, "Implementing Open Market Policy with Monetary Aggregate Objectives," in Federal Reserve Bank of New York, Monetary Aggregates and Monetary Policy (Federal Reserve Bank of New York, 1974), pp. 7-19; James L. Pierce, "Quantitative Analysis for Decisions at the Federal Reserve," Annals of Economic and Social Measurement, vol. 3 (January 1974), pp. 11-19; William Poole, "The Making of Monetary Policy: Description and Analysis," in Federal Reserve Bank of Boston, New England Economic Review (March/April 1975), pp. 21-30; and Richard G. Davis, "Role of Monetary Targets in Monetary Policy" (paper delivered at the Seventeenth Central Banking Seminar, Federal Reserve Bank of New York, April 5, 1977; processed).

14. I have discussed elsewhere the rationale and problems associated with the objective of preserving stability in the money market; see Benjamin M. Friedman, "Empirical Issues in Monetary Policy: A Review of Monetary Aggregates and Monetary Policy," Journal of Monetary Economics, vol. 3 (January 1977), pp. 87-101, 
range for the federal funds rate gives the manager some latitude to move this instrument as he thinks necessary for closer monetary control.

With only occasional minor variations, the Open Market Committee has continued to adhere to this basic two-stage structure in its operating approach. ${ }^{15}$ In addition, since early 1975 this procedure has become further formalized with the adoption by the Congress of House Concurrent Resolution 133, which requires the Chairman of the Federal Reserve Board to specify publicly, once each quarter, the current monetary-growth targets.

In the meanwhile, the advent of monetary-growth targets has not been limited to the United States. The Deutsche Bundesbank and the Swiss National Bank adopted this strategy in 1975, as have several other central banks since. Moreover, the Bank for International Settlements has officially endorsed this strategy, and the International Monetary Fund made its use by the Bank of England a precondition to its $\$ 3.9$ billion loan to Britain in 1977.

With so many countries following the monetary-target strategy, a closer examination of its merits is in order. Further understanding of how the procedure works and what tacit assumptions it entails is of value in itself, and any improvements that can be devised for such a widely applied policy procedure are well worth the effort.

\section{STRATEGY AND TACTICS OF MONETARY POLICY}

William Poole's demonstration of the conditions under which a moneystock approach to monetary policy dominates an analogous interest-rate approach, or vice versa, emphasized the distinction between separate disturbances arising from two aspects of economic behavior: ${ }^{16}$ First, the

and also, "The Information Value of Observing Monetary Policy Deliberations," discussion paper 550 (Harvard University, Harvard Institute of Economic Research, May 1977; processed).

15. For a discussion of the mercifully brief fiasco involving the role of reserves on private nonbank deposits, see Alan R. Holmes, Paul Meek, and Rudolf Thunberg, “Open Market Operations in the Early 1970's: Excerpts from Reports Prepared in 1971, 1972, and 1973," in Federal Reserve Bank of New York, Monetary Aggregates and Monetary Policy, pp. 114-34; and Friedman, "Empirical Issues in Monetary Policy."

16. Especially since the quadrupling of oil prices by the OPEC cartel and the subsequent severe recession in 1974-75, many economists have also emphasized "supply shocks" as a third major source of economic instability; see, for example, Stanley Fischer, "Wage-Indexation and Macro-economic Stability" (Massachusetts Institute of Technology, rev., March 1976; processed). 
greater the instability of the economy's spending behavior, for given interest rates and other factors, the less effective is a monetary-policy strategy based on controlling interest rates and the more effective by comparison is the alternative money-stock strategy. Second, the greater the instability of the economy's portfolio behavior (in particular the demand by the nonbank public for cash balances), for given interest rates and income and other factors, the less effective is a monetary-policy strategy based on controlling the money stock and the more effective by comparison is the alternative interest-rate strategy. In addition to the crucial role of these two stochastic elements, Poole showed how some of the deterministic aspects of economic behavior (especially the relative interest elasticities of the demand for cash balances and the demand for real commodities) also influence the comparative effectiveness of the alternative strategies.

In formal terms, Poole's analysis relied on a nondynamic two-equation stochastic Hicksian IS-LM model,

$$
\begin{gathered}
Y_{t}=a_{1} r_{t}+\mathbf{a}^{\prime} \mathbf{z}_{t}+u_{I S t} \\
M_{t}=b_{1} Y_{t}+b_{2} r_{t}+\mathbf{b}^{\prime} \mathbf{z}_{t}+u_{L M t},
\end{gathered}
$$

where

$$
Y=\text { income }
$$

$r=$ "the" interest rate

$\mathbf{z}=$ a vector of values of relevant variables exogenous to the monetary policy process (perhaps including fiscal policy)

$M=$ the money stock.

$a, b=$ fixed (and known) coefficients

$u_{I S}, u_{L M}=$ zero-mean disturbance terms corresponding to the IS and LM relations, respectively, with finite variances $\sigma_{I S}^{2}$ and $\sigma_{L M}^{2}$ and covariance $\sigma_{I S, L M}$.

The anticipated signs of the scalar coefficients are $b_{1}>0>a_{1}, b_{2}$; and $\mathbf{a}$ and $\mathbf{b}$ are vectors of coefficients applicable to all exogenous variables in $\mathbf{z}$, including the intercepts in the two equations and also including zeroes for cases in which an individual exogenous variable does not appear in either equation.

Since this two-equation system with three variables (other than $z$ ) is determined by taking either $r$ or $M$ to be exogenous, the model is a convenient device for analyzing the relative merits of the interest-rate and 
money-stock strategies. In particular, under the interest-rate strategy the implied reduced-form equation that determines income,

$$
Y_{t}=\theta r_{t}+\theta^{\prime} \mathbf{z}_{t}+\epsilon_{Y t},
$$

simply reduces to the IS curve, while under the money-stock strategy the analogous reduced-form equation for income,

$$
Y_{t}=\phi M_{t}+\phi^{\prime} \mathbf{z}_{t}+\zeta_{Y t},
$$

is a solved-out combination of the IS and LM curves together. ${ }^{17}$

If the objective of policy is to minimize the expected squared deviation of income from the corresponding desired level, say $Y_{t}^{*}$, then substituting $Y_{t}^{*}$ into either of equations 3 or 4 and solving the reduced form for either the interest rate or the money stock accordingly gives the respective optimal policies, say $r_{t}^{*}$ and $M_{t}^{*}{ }^{18}$ Both policies lead to the identical conditional expectation $E\left(Y_{t}\right)=Y_{t}^{*}$, but, since the two reduced-form disturbances $\epsilon_{Y t}$ and $\zeta_{Y t}$ differ, the corresponding expected squared deviations differ as well. The reduced-form equation 3 under the interest-rate strategy is simply the IS curve, so that

$$
\epsilon_{Y t}=u_{I S t}
$$

and the value of the policy objective is

$$
\sigma_{Y \mid r}^{2} \equiv E\left(\epsilon_{Y t}\right)^{2}=\sigma_{I S}^{2} .
$$

By contrast, the reduced-form equation 4 under the money-stock strategy combines the IS and LM curves, so that

$$
\zeta_{Y t}=\left(a_{1} b_{1}+b_{2}\right)^{-1}\left(b_{2} u_{I S t}-a_{1} u_{L M t}\right)
$$

17. The comparison of these two derived reduced forms rests on the assumption that the underlying economic behavior specified in the IS and LM curves is invariant to the central bank's choice of operating strategies. For a challenge to this assumption, see Robert E. Lucas, Jr., "Econometric Policy Evaluation: A Critique," in Karl Brunner and Allan H. Meltzer, eds., The Phillips Curve and Labor Markets (NorthHolland, 1976), pp. 19-46. Allowing for Lucas' point, which is based on the assumption of "rational" expectations on the part of the actors whose behavior is summarized in the IS and LM curves, would require analyzing the changes in the relevant behavior and would thereby take the analysis too far afield from the intended focus of this paper.

18. Poole also considered a "combination" policy focusing on both the money stock and the interest rate; see Poole, "Optimal Choice of Monetary Policy Instruments." An analog to this combination policy is especially relevant in the discussion below of the intermediate-target approach. 
and the value of the policy objective is

(8) $\sigma_{Y \mid M}^{2} \equiv E\left(\zeta_{Y t}\right)^{2}=\left(a_{1} b_{1}+b_{2}\right)^{-2}\left(b_{2}^{2} \sigma_{I S}^{2}-2 a_{1} b_{2} \sigma_{I S, L M}+a_{1}^{2} \sigma_{L M}^{2}\right)$.

Hence the superiority of either the interest-rate or the money-stock strategy, given by the comparison of the respective expected squared deviations $\sigma_{Y \mid r}^{2}$ and $\sigma_{Y \mid M}^{2}$, depends not only on the variance-covariance structure of the stochastic elements of the IS-LM model but also on the values of its three slope coefficients. The relevance of this normative analysis to the prior (and ongoing) discussion of positive issues is immediate. In particular, the familiar monetarist contention that the demand for money is both stable (that is, $\sigma_{L_{M}}^{2}$ is small in comparison to $\sigma_{I S}^{2}$ ) and interest inelastic ( $b_{2}$ is small in absolute value) directly implies the superiority of the money-stock approach. The choice of a monetary-growth target rather than an interest-rate target, at the strategy level of the twostage decision framework used by the Open Market Committee, therefore reflects a judgment that the underlying economic parameters are such that $\sigma_{Y \mid M}^{2}$ is indeed smaller than $\sigma_{Y \mid r}^{2}$.

The reason why there must be a tactics level of the two-stage monetarypolicy process is that, at a more realistic level of analysis, the Open Market Committee cannot simply exogenize the money stock. ${ }^{19}$ Instead, under the U.S. fractional-reserve banking system in which portfolio decisions by individual banks determine their net free reserves, the committee must affect the money stock indirectly by influencing the actions of banks and deposit holders. Other institutional features of the U.S. banking system, such as different reserve requirements on different classes of bank liabilities and the large (and variable) fraction of deposits held in banks that are not members of the Federal Reserve System, further complicate the determination of the money stock, over and above the more fundamental problem associated with banks' portfolio choices.

At the tactics level, the Open Market Committee again has a choicethis time of the instrument that it uses to control the money stock. As James Pierce and Thomas Thomson demonstrated, the second-stage choice between nonborrowed reserves (or the nonborrowed monetary base) and a short-term interest rate as the instrument for controlling

19. Poole's original paper also acknowledged this point; see ibid., p. 198. See also William Poole and Charles Lieberman, "Improving Monetary Control," BPEA, 2:1972, pp. 293-335. 
the money stock is analytically similar to the first-stage choice between the money stock and the interest rate as means of influencing income. ${ }^{20}$ The committee's current tactics, based on closely controlling the federal funds rate, essentially exploit the LM curve to influence the demand of the nonbank public for money balances. The alternative approach based on controlling nonborrowed reserves would exploit both money-demand behavior and a money-supply relation,

$$
M_{t}=c_{1} R_{t}+c_{2} r_{t}+\mathbf{c}^{\prime} \mathbf{z}_{t}+u_{M S t},
$$

where $R$ is the stock of reserves, $u_{M S}$ is a further disturbance comparable to $u_{I S}$ and $u_{L M}$, and the usually anticipated signs of the scalar coefficients are $c_{1}, c_{2}>0$. Whether reserves or the interest rate constitutes the better instrument therefore depends on the relative variances of the money-supply and money-demand disturbances, $\sigma_{M S}^{2}$ and $\sigma_{L M}^{2}$, on their covariance, and on the relative interest elasticities of money supply and money demand. ${ }^{21}$

Because the use of reserves as the policy instrument at the tactics level further complicates the analytics of the monetary-policy process-in that it necessitates working with the three-equation IS-LM-MS system, instead of the two-equation IS-LM system-the next section of the paper proceeds on the assumption that the Open Market Committee (as is its current practice) instead uses the interest rate for this purpose. ${ }^{22}$

\section{An Analysis of the Intermediate-Target Procedure}

The two-equation IS-LM model in the previous section illustrates in a straightforward way the fundamentally dynamic nature of the intermediate-target procedure for monetary-policy operations. The model shows

20. James L. Pierce and Thomas D. Thomson, "Some Issues in Controlling the Stock of Money," in Controlling Monetary Aggregates II: The Implementation, Proceedings of a Conference (Federal Reserve Bank of Boston, 1972), pp. 115-36. Subsequently, a growing literature on this subject has developed, mostly due to Federal Reserve staff researchers.

21. Once again, a "combination" policy involving both reserves and the interest rate is possible.

22. Since the empirical work presented below considers both alternatives, however, an appendix available from either the editors or the author briefly summarizes the corresponding results under the reserves approach. 
immediately that, in the nondynamic context developed above, there is no operational distinction between using the interest rate to influence the money stock so as in turn to influence income and simply using the interest rate directly to influence income. Solving the model's implied reducedform equation for the money stock, to find that value of the interest rate that equates the expectation of the money stock to the optimal $M_{t}^{*}$ under the money-stock strategy, shows that this value is identical to the optimal $r_{t}^{*}$ under the interest-rate strategy,

$$
r_{t}^{*}=\theta^{-1}\left(Y_{t}^{*}-\theta^{\prime} z_{t}\right) .
$$

Under either approach the money stock is an endogenous variable with expectation $M_{t}^{*}$, but in the nondynamic context this expectation is of no further significance.

\section{THE USEFULNESS OF THE PROCEDURE}

The key to the usefulness of the money stock (or any other variable) as an intermediate target emerges only in the context of a dynamic model -and, in particular, under the condition of some asymmetry in the flow of information to the policymaker. Three simple examples of such an asymmetry, each of which recalls some aspect of the actual circumstances of monetary policymaking, illustrate the concept of the intermediatetarget approach. ${ }^{23}$

Example 1-Continuous Monitoring. First, suppose that $Y_{t}, M_{t}$, and $r_{t}$ refer to the average levels of the corresponding economic variables within a given calendar quarter. Further suppose that, as of the beginning of any quarter $t$, the Open Market Committee has no information suggesting nonzero expectations for either the IS curve disturbance $u_{I S t}$ or the LM curve disturbance $u_{L M t}$. Then the committee's optimal policy is simply $r_{t}^{*}$ as in equation 10, which in turn implies $E\left(Y_{t}\right)=Y_{t}^{*}$ and $E\left(M_{t}\right)=M_{t}^{*}$.

To introduce the necessary asymmetry in the information flow, next suppose that as the quarter proceeds the committee receives monthly (or

23. The structure of each of these examples follows my earlier paper, "Targets, Instruments and Indicators of Monetary Policy," Journal of Monetary Economics, vol. 1 (October 1975), pp. 443-73. In addition, the first example, based on continuous monitoring, draws on John H. Kareken, Thomas Muench, and Neil Wallace, "Optimal Open Market Strategy: The Use of Information Variables," American Economic Review, vol. 63 (March 1973), pp. 156-72. 
even weekly or daily) observations of the money stock but not of income. ${ }^{24}$ After one month, therefore, it may learn that the money stock is instead turning out to equal some value $M_{t} \neq M_{t}^{*}$. Income may also be turning out to equal some value $Y_{t} \neq Y_{t}^{*}$, but the committee has no direct information that such is the case.

The essence of the intermediate-target approach to monetary policy under such circumstances is for the committee to act as if its objective were to make the money stock meet, as closely as possible, the expectation $M_{t}^{*}$ which prior analysis has shown to be consistent with the expectation of income equaling the desired $Y_{t}^{*}$. To carry over the quadratic criterion, the intermediate-target procedure consists of setting policy as if the minimand were $E\left(M_{t}-M_{t}^{*}\right)^{2}$ rather than $E\left(Y_{t}-Y_{t}^{*}\right)^{2}$. Since the ultimate target of policy in this simplified model is income, the nomenclature "intermediate target" distinguishes the role of the money stock as that of a means to an end rather than an end in itself.

This strategy is useful because the actual evolution of the money stock during the quarter, for the given interest rate $r_{t}^{*}$, follows from the relevant reduced-form equation of the IS-LM model as

$$
M_{t}=M_{t}^{*}+u_{L M t}+b_{1} u_{I S t},
$$

so that a deviation of the money stock from expectation $M_{t}^{*}$ is in general due, at least in part, to a disturbance in the economy's spending behavior. If the committee could also monitor income within the quarter, so that it could get a direct indication of the emergence of a disturbance $\epsilon_{\mathrm{Y} t} \neq 0$, then the optimal policy after one month of the quarter would be not to continue $r_{t}^{*}$ as in equation 10 but instead to implement a revised policy that follows from solving out the reduced form 3-that is, the IS curve in this simple model-as

$$
\begin{aligned}
r_{t}^{* *} & =\theta^{-1}\left[Y_{t}^{*}-\theta^{\prime} \mathbf{z}_{t}-E_{m}\left(\epsilon_{Y}\right)\right] \\
& =r_{t}^{*}-a_{1}^{-1} E_{m}\left(u_{I S t}\right),
\end{aligned}
$$

where $E_{m}(\cdot)$ indicates the expectation conditional on the new information received during the first month of the quarter. Information indicating a random surge in spending therefore leads to an increase in the appropriate interest rate, while information indicating a shortfall leads to a

24. The committee presumably can observe the interest rate too; but, since it is simply setting this variable at $r_{t}^{*}$, no information is contained in such observations. 
reduction. A similar adjustment process would obtain after the second month of the quarter-or after any within-quarter observation of income.

Since the committee cannot directly monitor income within the quarter, however, it cannot directly implement the revised optimal interest rate $r_{t}^{* *}$ in equation 12. By contrast, since the money stock is observable within the quarter, the committee can adjust the interest rate so as to bring the money stock as close as possible to the previously selected $M_{t}^{*}$-that is, it can treat the money stock as its intermediate target variable. To the extent that the emerging difference between $M_{t}$ and $M_{t}^{*}$, indicated by the withinquarter observation, is due to a disturbance in spending behavior-as equation 11 shows that in general it will be, at least in part-the intermediate-target procedure based on the money stock is therefore equivalent to a particular way of using incoming money-stock observations to infer information about the disturbance $u_{I S t}$ and then adjusting the implemented policy on the basis of that information.

Example 2-Data Lags. As a second illustration of the role of an information asymmetry in lending operational content to the intermediatetarget approach, suppose that the Open Market Committee observes all variables only once per quarter, just at the quarter's end. Further suppose that, while each quarter's value of the money stock is observable at the end of that same quarter, income is observable only after a lag of at least one quarter. Given this asymmetry, a generalization of the IS-LM model that again illustrates the essential features of the intermediatetarget procedure is to assume that the respective disturbances of the two behavioral equations are serially correlated:

$$
\begin{aligned}
u_{I S t} & =\rho_{I S}\left(u_{I S, t-1}\right)+v_{I S t} \\
u_{L M t} & =\rho_{L M}\left(u_{L M, t-1}\right)+v_{L M t},
\end{aligned}
$$

where $-1<\rho_{I S}, \rho_{L M}<1$, and $v_{I S}$ and $v_{L M}$ both have zero mean, finite variance, and zero serial correlation.

As of the beginning of quarter $t$, then, when the committee must determine and implement the optimal interest rate, $M_{t-1}$ is known but $Y_{t-1}$ is not. Since the committee therefore cannot compare the actual $Y_{t-1}$ against the prior expectation $Y_{t-1}^{*}$ to solve out the spending disturbance $u_{I S, t-1}$, it cannot simply apply the serial-correlation structure $\rho_{I S}$ to determine directly a nonzero expectation to use in selecting the optimal interest rate for the current quarter according to 


$$
\begin{aligned}
r_{t}^{* *} & =\theta^{-1}\left[Y_{t}^{*}-\theta^{\prime} \mathbf{z}_{t}-E_{Y_{t-1}}\left(\epsilon_{Y t}\right)\right] \\
& =r_{t}^{*}-a_{1}^{-1} E_{Y_{t-1}}\left(u_{I S t}\right),
\end{aligned}
$$

where $r_{t}^{*}$ is again as in equation 10 and $E_{Y_{t-1}}(\cdot)$ indicates the expectation conditional on the (nonexistent) observation of income in the previous quarter ${ }^{25}$ By contrast, what is possible under these circumstances is to use the indirect serial correlation of $\left(M-M^{*}\right)$ to infer a nonzero expectation of the current $\left(M_{t}-M_{t}^{*}\right)$ from the observed $\left(M_{t-1}-M_{t-1}^{*}\right)$ according to

$$
E_{M t-1}\left(M_{t}-M_{t}^{*}\right)=\rho_{M}\left(M_{t-1}-M_{t-1}^{*}\right),
$$

where $E_{M_{t-1}}(\cdot)$ indicates the expectation conditional on the observation of the money stock in the previous quarter, and $\rho_{M}$ is the "serial-correlation coefficient" calculated from the history of surprises in the observed money stock $\left(M-M^{*}\right)$. While the committee cannot directly implement the revised optimal interest rate $r_{t}^{* *}$ in equation 14, therefore, it can use the expectation in 15 to set the interest rate for quarter $t$ at the level that will bring the money stock as close as possible to the previously selected $M_{t}^{*}$; that is, it can treat the money stock as its intermediate target variable. To the extent that the observed difference between $M_{t-1}$ and $M_{t-1}^{*}$ was due to a disturbance in spending behavior-as equation 11 lagged one quarter shows that in general it will be, at least in part-the intermediatetarget procedure based on the money stock is therefore equivalent to a particular way of using the available money-stock observation from quarter $t-1$ to infer information about the disturbance $u_{I S t}$ and then adjusting policy for quarter $t$ accordingly.

Example 3-Structural Lags. As a final illustration of the intermediatetarget procedure in the context of an information asymmetry, suppose, first, that the interest rate (as well as the other exogenous variables) affects spending behavior only after a one-quarter lag and, second, that people hold money balances in anticipation of future spending. Hence it is always too late for monetary policy to have any impact on income in the

25. The committee does, however, have the observation $Y_{t-T}$, which permits solving for $u_{I S, t-T}$, for some data lag of $T$ quarters, and this information too is useful. For an analysis of the relative value of this information, see my "Targets, Instruments, and Indicators." 
current quarter, so that the focus of monetary policy is on future income. Rewriting the IS-LM model accordingly yields

$$
\begin{gathered}
Y_{t+1}=a_{1} r_{t}+\mathbf{a}^{\prime} \mathbf{z}_{t}+u_{I S, t+1} \\
M_{t}=b_{1} Y_{t+1}+b_{2} r_{t}+\mathbf{b}^{\prime} \mathbf{z}_{t}+u_{L M t} .
\end{gathered}
$$

Further suppose that the IS and LM disturbances are again serially correlated as in equation 13, and that the value of both income and the money stock in each quarter is observable just at the end of the quarter with no lag.

The Open Market Committee's objective in this situation is to set the interest rate, during quarter $t$, so as to minimize the quadratic criterion $E\left(Y_{t+1}-Y_{t+1}^{*}\right)^{2}$. Given only the knowledge of the model and the exogenous variables as before, the optimal policy follows, analogously to equation 10 , as

$$
r_{t}^{*}=\theta^{-1}\left(Y_{t+1}^{*}-\theta^{\prime} \mathbf{z}_{t}\right) .
$$

At the beginning of quarter $t, M_{t-1}$ is known but of course $Y_{t}$ is not. Hence again the committee cannot directly discover the current quarter's spending disturbance $u_{I S t}$ so that they can use it together with the serial-correlation structure $\rho_{I S}$ to calculate the optimal interest rate according to

$$
r_{t}^{* *}=r_{t}^{*}-a_{1}^{-1} E_{Y_{t}}\left(u_{I S, t+1}\right),
$$

where $r_{t}^{*}$ is as in equation 10 and $E_{Y_{t}}(\cdot)$ indicates the expectation conditional on the (nonexistent) observation of $Y_{t}{ }^{26}$

What is possible, as in the analogous example of the data lag, is to use the indirect serial correlation of $\left(M-M^{*}\right)$ to infer a nonzero expectation of the current $\left(M_{t}-M_{t}^{*}\right)$ from the observed money-stock surprise $\left(M_{t-1}-M_{t-1}^{*}\right)$ according to equation 15, and then to use that expectation to set the interest rate for quarter $t$ so as to bring the money stock as close as possible to the previously selected $M_{t}^{*}$; that is, once again the committee can treat the money stock as an intermediate target variable. To the extent that the observed difference between $M_{t-1}$ and $M_{t-1}^{*}$ was due to a disturbance (of course, unobservable) in the current quarter's spending behavior-as the analog to equation 11 derived from $1^{\prime}$ and $2 '$ shows that in general it will be, at least in part-the intermediate-target procedure based on the money stock is equivalent to a particular way of using the

26. Once again, the committee does have the observation $Y_{t-1}$; see note 25 . 
money-stock observation from quarter $t-1$ to infer information about the disturbance $u_{I S, t+1}$ and then adjusting policy for quarter $t$ accordingly.

As all three of these simple illustrations show, a policy procedure focusing on an intermediate target variable is a logically definable concept with operational content in a dynamic stochastic world with some source of asymmetry in the flow of new information. This rendering is fully consistent with the earlier definition by Karl Brunner and Allan Meltzer of an intermediate-target procedure as a means of choosing optimal monetary policy under conditions of uncertainty and delays in the receipt of information about the ultimate policy targets. ${ }^{27}$ That the intermediate-target procedure can be of benefit in policymaking under these conditions is clear. Whether it will necessarily be of benefit and whether it constitutes the best operating procedure under actual operating conditions remain to be discovered.

\section{THE INEFFICIENCY OF THE}

\section{INTERMEDIATE-TARGET PROCEDURE}

As the discussion above makes clear, the basic usefulness of the intermediate-target approach to monetary policymaking is as a processor of information. Only observations of endogenous variables that differ from prior expectations can provide new information in this simplified setting, and the procedure based on the money stock as an intermediate-target variable amounts to a specific way of using the information contained in such observed differences in the money stock. In particular, the intermediate-target procedure is equivalent to using this information first to draw inferences about the unobservable stochastic disturbance in the economic behavior proximately determining income, the ultimate target of policy, and then to adjust monetary policy in light of those inferences.

Is the specific way of processing this information embodied in the intermediate-target approach the best way? Except under extremely restrictive conditions, the answer is no.

In example 1 above (monitoring of the money stock but not income within the quarter), the intermediate-target procedure amounts to imple-

27. Karl Brunner and Allan H. Meltzer, "The Meaning of Monetary Indicators," in George Horwich, ed., Monetary Process and Policy: A Symposium (Irwin, 1967), pp. 187-217. Brunner and Meltzer emphasized the asymmetry due to more rapid collection of data on financial variables, as in examples 1 and 2; as example 3 shows, however, the data-lag and structural-lag asymmetries are analytically equivalent. 
menting, in place of the policy indicated in equation 12 based on the missing direct expectation of $u_{I S t}$, the alternative policy

$$
r_{t}^{* *}=r_{t}^{*}-\psi^{-1}\left(M_{m}-M_{t}^{*}\right),
$$

where $\psi$ is the coefficient of the interest rate in the solved-out reducedform equation for the money stock in the IS-LM model, and $M_{m}$ is the observation of the money stock after the first month of the quarter ${ }^{28}$ Given that the ultimate target of monetary policy is income and not the money stock, using policy 16 in place of policy 12 in turn implies an assumption that the information contained in the observed $\left(M_{m}-M_{t}^{*}\right)$ carries over directly to the crucial spending disturbance $u_{I S t}$. In particular, equating the right-hand sides of equations 12 and 16 shows, after substituting for the two reduced-form coefficients $\theta$ and $\psi$, that the intermediate-target approach processes this information to derive the relevant expectation as

$$
E_{m}\left(u_{I S t}\right)=\left(a_{1} b_{1}+b_{2}\right)^{-1} a_{1}\left(M_{m}-M_{t}^{*}\right) .
$$

Is this expression the best available estimate of the missing expectation for the IS curve disturbance? As equation 11 indicates, the moneystock surprise $\left(M_{m}-M_{t}^{*}\right)$ consists of a combination of both the IS and LM disturbances, with the former weighted by the income elasticity of money demand. Given this composite nature of $\left(M_{m}-M_{t}^{*}\right)$, it follows that the correct minimum-variance expression for the missing expectation is not equation 17 but instead

$$
\begin{aligned}
& E_{m}\left(u_{I S t}\right) \\
& \qquad=\left(\sigma_{L M}^{2}+2 b_{1} \sigma_{I S, L M}+b_{1}^{2} \sigma_{I S}^{2}\right)^{-1}\left(b_{1} \sigma_{I S}^{2}+\sigma_{I S, L M}\right)\left(M_{m}-M_{t}^{*}\right) .
\end{aligned}
$$

Under the restrictive conditions that $\sigma_{L M}^{2}=\sigma_{Y, L M}=0$ (that is, money demand is perfectly stable) and $b_{2}=0$ (money demand is perfectly interest inelastic), the two methods of inferring the disturbance in spending behavior from the observed money surprise are identical, so that the policy embodied in equation 16 implemented under the intermediatetarget approach is identical to the correct optimal policy indicated by sub-

28. If the money stock is supposed to be growing during the quarter, then the correct right-hand-side variable in 16 is not $\left(M_{m}-M_{t}^{*}\right)$ but $\left(M_{m}-M_{m}^{*}\right)$, where $M_{m}^{*}$ is the first-month average money stock that some subsidiary relation indicates is consistent with achieving the average $M_{*}^{*}$ for the quarter. 
stituting the correct expectation 18 into $12 .{ }^{29}$ In the absence of perfect stability and interest inelasticity of money demand, however, the expectations in 17 and 18 in general are not identical, so that the policy implemented under the intermediate-target procedure is inferior to the optimal policy given by combining 12 and 18 .

The intuitive appeal of this result is straightforward. As the discussion above of the merits of the intermediate-target procedure demonstrates, the procedure is useful to the extent that the emerging difference between $M_{t}$ and $M_{t}^{*}$ is due to the (as yet unobserved) spending disturbance $u_{I S t}$. If money demand is perfectly stable, then in the simple IS-LM model $u_{I S t} \neq 0$ is the only reason for observing $M_{t} \neq M_{t}^{*}$, so that the procedure reduces to using the observed money surprise, divided by the income elasticity of money demand, to infer the key expectation of $u_{I S t}$. In addition, if money demand is perfectly interest inelastic, there is no need to allow for the slope of the LM curve in adjusting policy so as to offset this correctly inferred expectation. If money demand includes stochastic disturbances or is interest elastic, however, then the inference-and-adjustment mechanism implied by the intermediate-target procedure does not in general constitute the best way of using the information contained in the observed money surprise. In particular, the optimal policy consists of first determining how much of the money surprise is likely to be due to a spending disturbance (thereby warranting an offsetting policy action) and then allowing for the slope of the LM curve in gauging the proper offsetting policy.

The same conclusion also follows for example 2 (the data lag in observing income) and the directly analogous example 3 (the structural lags). In place of the policy in equation 14 based on the missing observation of $Y_{t-1}$, for example, the intermediate-target procedure in this situation amounts to implementing the alternative policy

$$
\begin{aligned}
r_{t}^{* *} & =r_{t}^{*}-\psi^{-1} E_{M_{t-1}}\left(M_{t}-M_{t}^{*}\right) \\
& =r_{t}^{*}-\psi^{-1} \rho_{M}\left(M_{t-1}-M_{t-1}^{*}\right),
\end{aligned}
$$

where the relevant expectation is from equation 15 . Using policy 19 in place of 14 is in turn equivalent, upon substitution for the indirect serialcorrelation coefficient $\rho_{M}$, to processing the information contained in the observed money surprise from the previous quarter so as to derive the

29. If the money stock is continuously observable and the interest rate continuously adjustable, the correct optimal policy is equivalent to Poole's "combination policy"; see Poole, "Optimal Choice of Monetary Policy Instruments." 
associated expectation of the disturbance in spending behavior in the current quarter according to

$$
\begin{aligned}
& E_{M t-1}\left(u_{I S t}\right)=\left(a_{1} b_{1}+b_{2}\right)^{-1} a_{1}\left(\sigma_{L M}^{2}+2 b_{1} \sigma_{I S, L M}+b_{1}^{2} \sigma_{I S}^{2}\right)^{-1} \\
& \quad \times\left[\rho_{L M} \sigma_{L M}^{2}+b_{1}\left(\rho_{I S}+\rho_{L M}\right) \sigma_{I S, L M}+b_{1}^{2} \rho_{I S} \sigma_{I S}^{2}\right]\left(M_{t-1}-M_{t-1}^{*}\right),
\end{aligned}
$$

when, by contrast, the correct expression for the missing expectation is the simpler ${ }^{30}$

$$
\begin{aligned}
E_{M t-1}\left(u_{I S t}\right)=\left(\sigma_{L M}^{2}+2 b_{1} \sigma_{I S, L M}+b_{1}^{2} \sigma_{I S}^{2}\right)^{-1} \\
\\
\quad \times\left(b_{1} \rho_{I S} \sigma_{I S}^{2}+\rho_{I S} \sigma_{I S, L M}\right)\left(M_{t-1}-M_{t-1}^{*}\right) .
\end{aligned}
$$

Once again, only under the restrictive conditions that the moneydemand function is perfectly stable and perfectly interest inelastic are the two methods of inferring the relevant expectation-and hence the two policies-necessarily identical. Conversely, if the demand of the nonbank public for money balances includes stochastic disturbances or is interest elastic, then by following the intermediate-target approach the Open Market Committee in general is not optimally exploiting the information contained in observations of the money stock.

Hence the intermediate-target procedure for monetary policy is a useful information processor but in general an inefficient one in that its inference-and-adjustment mechanism is not, except under highly restrictive conditions, the best way to exploit the information contained in money-stock observations. The third section of the paper uses a somewhat generalized econometric IS-LM model to provide some empirical sense of the extent of this inefficiency.

\section{A SECOND INEFFICIENCY OF THE PROCEDURE}

What about information from sources other than the money stock? Not only does the intermediate-target procedure fail to process efficiently the information contained in observations of the money stock, it also excludes from the policy-adjustment process any information not contained in such observations. Since information is (by definition) the scarce resource in models of policy formulation under uncertainty, it can hardly be optimal to disregard available information simply because it

30. This expression uses only the information contained in $\left(M_{t-1}-M_{t-1}^{*}\right)$ and excludes older observations on income; again see note 25 . 
originates from a source other than the single variable selected as the intermediate target.

It is important in this context to distinguish between two applications of new information under the intermediate-target procedure: first, using new information to select a new monetary target $M^{*}$ that is more likely to be consistent with the desired income target $Y^{*}$; and, second, using new information to determine how to manipulate the interest rate so as to achieve the original $M^{*}$ as closely as possible. In the extreme world of a constant-monetary-growth rule, in which the central bank would never change the setting of the intermediate-target variable, the only use that monetary policy would make of new information is in the latter sense of continually adjusting its instrument(s) to maximize the precision of monetary control around the fixed growth path. No new information would alter the monetary policymakers' views about the relationship between income, or other ultimate targets of policy, and money. (At the other extreme, if the central bank changed the setting of its monetary target every time it received new information and therefore was prepared to change its instrument setting, then it would not have an intermediate target in any operational sense.)

At least in the United States, however, the Federal Reserve System has not adopted a rule of constant monetary growth. Instead, as the discussion in the first section explains, once each quarter the Open Market Committee selects the targeted rate of monetary growth (which, given the past quarter's observation $M_{t-1}$, is equivalent to target $\left.M_{t}^{*}\right)$. At least in principle, therefore, the committee takes advantage once a quarter of the opportunity to reassess the money-income relationship and determine what $M_{t}^{*}$ value is consistent with achieving its ultimate objectives. Consequently, it is only the within-quarter flow of new information that the intermediate-target procedure necessarily precludes the committee from exploiting.

The discussion above frames the intermediate-target procedure in the context of the simple IS-LM model and shows that the procedure is inefficient in failing to allow adequately for the composite nature of surprises in observed movements of the money stock, so that policy acts to offset all such surprises regardless of their source. Because of its highly simplified structure, the IS-LM model contains no additional source, beyond observations of the money stock itself, of information pertinent to the key expectation required in equation 12 or 14 . In the more compli- 
cated world in which monetary policy actually operates, however, what clues are available to help the committee determine why the observed money stock is deviating from the targeted path, so that it will know whether or not to offset the deviation? Further, since this more complicated world contains more than one source of income variation, what additional clues are available to help the committee directly anticipate disturbances to income?

Since the relevant criterion here is the practical rather than the theoretical usefulness of information, these questions are answerable only at the empirical level. Nevertheless, it is possible to suggest a priori at least three realms, progressively further removed from the direct operation of monetary policy, in which to look for such information.

First, the Federal Reserve collects from the banking system a vast amount of data beyond money-stock observations. The discussion in the first section, for example, has introduced an equation, 9, representing banks' portfolio behavior, based on reserves and the interest rate, which determines money supply. When the Open Market Committee uses the federal funds rate as its policy instrument, this bank-behavior relationship determines the stock of reserves as a further endogenous variable. ${ }^{31}$ Since money, reserves, and the interest rate can all be conveniently monitored within the quarter, the emerging reserves surprise may be of further use. In particular, since it is possible to compute the bank-behavior disturbance $u_{M S}$ directly from $M, R$, and $r$, knowing this disturbance may augments useful information unless the associated covariances $\sigma_{I S, M S}$ and $\sigma_{L M, I S}$ are both zero; and so may knowing other easily available data on the banking system and other financial aggregates. Empirical results based on "semi-reduced-form" regressions of nominal income (not shown here) indicate that several nonmonetary financial aggregates-including bank credit, bank loans, total credit, and total liquid assets, each of which is readily observable on a current basis, just like the money stockcontain information about income that is not already contained in the monetary aggregates. ${ }^{32}$ The fact that monetary policy cannot exert even

31. Similarly, when the committee uses reserves as its instrument, the addition of equation 9 enables the IS-LM-MS model to determine the interest rate endogenously.

32. These regressions, estimated with quarterly seasonally adjusted data for the United States for the 1961:1-1976:2 sample period, follow the St. Louis pattern. Tests based on the $F$ statistic show, usually at the 99 percent confidence level, that these nonmonetary aggregates, either singly or in pairs, provide additional explanatory power in equations that already include federal high-employment expenditures and both $\mathbf{M}_{1}$ and $\mathbf{M}_{2}$. 
reasonably close short-run control over some of these aggregates (especially total credit and total liquid assets) as intermediate-target variables in no way precludes their use as "information" variables.

Second, the notion of "the" interest rate inherent in the IS-LM model is clearly an artifice in a world of multiple assets. Even as a first approximation, the interest rate that presumably matters most for money demand is a short-term yield, while the interest rate that matters most for spending is a long-term yield (or complex of yields) that, for a given short-term yield, follows from economic behavior in the asset markets. A stochastic disturbance in the relevant asset-market behavior will contribute directly both to a deviation of income from $Y_{t}^{*}$ and to a deviation of the money stock from $M_{\imath}^{*}$ (though not in identical ways); and, conversely, disturbances in spending behavior will also be reflected in developments in asset markets. Since both disturbances are in part reflected in readily observable interest-rate and equity-price relationships, observed patterns of asset prices and yields, as well as other financial-market measures beyond the banking-sector variables, can provide further information useful either for resolving the compound nature of money surprises or for forming independent expectations about income disturbances.

Third, while income in the sense of gross national product is observable only once a quarter, ${ }^{33}$ a great many sources of directly pertinent nonfinancial data are available more frequently: personal income, labor force and employment, wholesale and consumer prices, industrial production, retail sales, business inventories, housing starts, automobile sales, and many more. These variables, too, can help determine why the money stock is evolving differently from expectations-thereby indicating how monetary policy should react-and can also help provide direct estimates of the relevant income disturbance.

In principle, any of these three kinds of variables can serve as such an "information variable"; indeed, the discussion above demonstrates that an intermediate-target variable is merely a special case of the more general use of one or more such information variables. ${ }^{34}$ An unfortunate consequence of the Open Market Committee's desire to have not just information variables but intermediate targets, however, is that it has led to an emphasis on "controllability" which has little to do with the

33. Even so, the Commerce Department regularly revises the national income and product accounts between its new quarterly estimates.

34. See Kareken and others, "Optimal Open Market Strategy," for a detailed elaboration of the information-variable concept. 
underlying purpose of the intermediate-target approach as a processor of information. Although any readily observable variable reliably related to the ultimate targets of policy is a useful information variable, only variables over which the committee can exert fairly close control represent plausible candidates as intermediate targets; ${ }^{35}$ and the pursuit of the intermediate-target approach hinders the exploitation of the remaining potential information variables that are not intermediate targets.

Hence the intermediate-target procedure based on the money stock is also inefficient in that it fails to exploit fully the information contained in observations of variables other than the intermediate target itself. It may well be true that the money stock is a highly important source of information about likely outcomes for the ultimate targets of monetary policy; it is even possible that it is the best such source. Nevertheless, that the money stock is the only practically exploitable source of this information, or that it already contains all information available from other sources, is highly implausible.

\section{Evaluating the Inefficiency of the Intermediate-Target Procedure}

The discussion in the previous section shows at the conceptual level that the intermediate-target procedure for monetary policy, based on the money stock, is in general an inefficient means of processing the information contained in observations of the money stock. ${ }^{36}$ How important is this inefficiency in practice?

35. The greater "endogeneity" of bank credit since the removal in 1970 of the Regulation Q ceiling on interest paid on large certificates of deposit, for example, is sometimes cited as a reason for preferring money as the intermediate target. Since mid-1970, the observed correlations between nominal income and almost any measure of bank credit have increased dramatically, while the corresponding correlations between bank-credit measures and money have fallen; see David E. Lindsey, "The Relationship of GNP to Various Money and Credit Aggregates" (Board of Governors of the Federal Reserve System, October 1976; processed), table 5. As the discussion above makes clear, however, such endogeneity in no way disqualifies an information variable for purposes of short-run monetary policy.

36. I am grateful to Franco Modigliani for many extremely helpful conversations about the construction of this model. For reasons that are apparent in the discussion below, I have come to refer to the model (once the nominal-income identity is added) as "the Pirandello model." 
A SMALL MACROECONOMETRIC MODEL

As a comparison of the alternative expectations 17 and 18 -or, analogously, 20 and 21-shows, the extent of this inefficiency is an empirical matter which depends on the economy's underlying stochastic features, including the relevant variance-covariance and serial-correlation structures, as well as on some of the deterministic aspects of economic behavior. Evaluating this inefficiency, therefore, calls for some convenient empirical model. The five-equation macroeconometric model of the United States developed for this purpose here is a "bare essentials" model, in the sense that it is impossible to reduce it to fewer variables and equations without grossly distorting fundamental notions of macroeconomic behavior. The model expands on the two-equation IS-LM model used throughout the first two sections of the paper in three respects: First, the model resolves the ambiguity of real-dollar versus nominal-dollar magnitudes by expressing the "income" variable in the IS curve in real terms and adding a separate price-setting equation, leaving nominal income to be determined by the appropriate identity relation. Second, the model includes an equation for bank-portfolio behavior comparable to equation 9 , thereby facilitating the analysis of monetary policy also under the assumption that the Open Market Committee adopts the stock of reserves as its policy instrument. Third, as the discussion in the second section anticipates, the model identifies "the" interest rate most relevant for behavior of money demand and money supply as a short-term rate and "the" interest rate most relevant for behavior of spending as a longterm rate, and adds a simple term-structure equation relating the two. ${ }^{37}$

It is of the utmost importance to emphasize that, in the construction of this macroeconometric model for purposes of this paper, the primary objectives have been compactness and simplicity in the interest of analytical tractability and easy understanding. The model has only five stochastic equations (IS curve, price setting, LM curve, money supply, and term structure), hence five endogenous variables; and, apart from the autoregressive terms, only four exogenous variables-one each for monetary

37. It is only with great reluctance, in the interest of preserving the model's compactness, that $I$ have used a term-structure equation in place of a pair of supply and demand equations for long-term assets, comparable to the LM and MS equations; see my "Financial Flow Variables and the Short-Run Determination of Long-Term Interest Rates," Journal of Political Economy, vol. 85 (August 1977), pp. 661-89. 
policy, fiscal policy, and debt-management policy, and one for the foreign sector. All of the economic relationships included in the model are of the most familiar, fundamental sort. No variable appears explicitly in the model lagged more than one quarter, so that all lag structures are of the implicit Koyck form. ${ }^{38}$ All of the equations are linear in the logarithms of the economic variables.

In the absence of the extensive disaggregation, elaborate lists of exogenous variables, complex lag structures, and nonlinear specifications that characterize modern large-scale macroeconometric modeling, therefore, this model is clearly neither the latest practical tool for forecasting or policy planning nor the most comprehensive summary of current knowledge of the U.S. economy. Instead, the model's purpose is to indicate the rough orders of magnitude of the respective variances, covariances, serial correlations, and slope coefficients corresponding to those that figure prominently in the previous section's analytical discussion of the inefficiency of the exploitation by the intermediate-target approach of the information contained in observations of the money stock. Unlike largescale complex models, the compact linear model yields direct estimates of these magnitudes. Nevertheless, as the discussion below shows, the model itself is quite interesting in a number of further respects.

The model was estimated, using seasonally adjusted quarterly data for the United States over the sample period 1961:1-1976:2, by (with one exception noted below) Ray Fair's limited-information method for simultaneous equations with lagged dependent variables and first-order serially correlated disturbances. ${ }^{39}$ Except for the term-structure equation, all of the model's specifications are in first differences (and hence impose the assumption that the disturbances in the corresponding level specifications follow random walks). All variables are expressed in natural logarithms, so that these differences in turn correspond to percentage changes (or growth rates).

38. Using polynomial distributed-lag techniques, for example, would probably have improved the within-sample fit of at least several of the equations, since the available econometric evidence indicates that some of the lag structures represented in the model are more likely concave from the origin than convex.

39. Ray C. Fair, "The Estimation of Simultaneous Equation Models with Lagged Endogenous Variables and First Order Serially Correlated Errors," Econometrica, vol. 38 (May 1970), pp. 507-16. The precise method used corresponds to that indicated in section 4 of Fair's paper as the correct way of estimating the model's asymptotic variance-covariance matrix. 
Since the model includes two alternative instruments of monetary policy, reserves and the short-term interest rate, it is necessary for purposes of the instrumental-variables estimation procedure to designate the one presumed to have been exogenous during the sample period. This question is far from straightforward in a quarterly time frame, despite the fact that the Open Market Committee has typically acted so as to set a short-term interest rate over much briefer intervals. To guard against erroneous conclusions, therefore, the model was estimated twice-once with reserves treated as exogenous, and once with the short-term interest rate treated as exogenous. In fact, the two sets of estimates did not differ in any apparently interesting way. The estimates presented below and subsequently used to analyze the intermediate-target procedure are those for reserves treated as exogenous. ${ }^{40}$

The estimates of the model's five behavioral equations are given in expressions I through $\mathrm{V}$, where the symbols are defined as follows:

$E=$ high-employment federal expenditures

$I=$ price deflator for dollar-denominated imports $(1972=1.0)$

$L=$ face amount of outstanding federal securities maturing in more than one year (beginning of quarter)

$M=$ money stock, $\mathrm{M}_{2}$ (currency plus demand and time deposits plus certificates of deposit under $\$ 100,000)$

$P=$ price deflator for gross national product $(1972=1.0)$

$R=$ nonborrowed reserves, adjusted for changes in reserve requirements, less reserves required against government deposits

$r_{L}=$ long-term interest rate (Moody's Baa corporate bonds), in percent

$r_{S}=$ short-term interest rate (three-month Treasury bills), in percent

$S=$ face amount of outstanding federal-government securities maturing in less than one year (beginning of quarter)

$X=$ real gross national product

$Y=$ nominal gross national product.

All variables are expressed in natural logarithms, and, except for $r_{L}$ and $r_{S}$, are seasonally adjusted. All dollar amounts are expressed in bil-

40. Occasional footnotes along the way indicate the corresponding results based on the alternative estimates with the short-term interest rate treated as exogenous. 
lions of current dollars, except $E$ and $X$, which are in billions of 1972 dollars. The numbers in parentheses are (asymptotic) $t$ statistics, and $\vec{R}^{2}$ is the adjusted coefficient of multiple determination of the untransformed variables.

(I)

$$
\begin{aligned}
\Delta X_{t}= & 0.00614+0.451 \Delta X_{t-1}+0.113 \Delta E_{t} \\
& (3.7) \quad(4.0) \\
& -0.0948 \Delta r_{L t}-0.101 \Delta I_{t-1} . \\
& (-2.7) \quad(-2.9)
\end{aligned}
$$

Standard error $=0.00761 ; \bar{R}^{2}=0.63 ; \rho=-0.373$.

(II)

$$
\Delta(M-P)_{t}=\underset{(4.3)}{0.692 \Delta(M-P)_{t-1}+0.362 \Delta X_{t}-0.0512 \Delta r_{S t} .}
$$

Standard error $=0.00617 ; \bar{R}^{2}=0.58 ; \rho=-0.106$.

$$
\begin{aligned}
& \Delta M_{t}=0.950 \Delta M_{t-1}+0.0726 \Delta R_{t}-0.0165 \Delta r_{s t} . \\
& \text { (25.0) }
\end{aligned}
$$

$$
\begin{aligned}
r_{L t}= & 0.000546+0.902 r_{L, t-1}+0.265 r_{S t} \\
& (0.1) \quad(19.0) \quad(4.4) \\
& -0.137 r_{S, t-1}+0.0535 \Delta(L-S)_{t-1} . \\
& (-2.8) \quad(1.7)
\end{aligned}
$$

$$
\text { Standard error }=0.0234 ; \bar{R}^{2}=0.97 ; \rho=0.592 \text {. }
$$

The nominal income identity is

$$
\Delta Y_{t} \equiv \Delta X_{t}+\Delta P_{t} .
$$

While the model is fairly straightforward, it is interesting to comment in particular on a few aspects of the estimation results.

The IS curve, equation I, relates real spending to federal expenditures measured on a high-employment basis, to the dollar-denominated price of U.S. imports (lagged one quarter), and to the long-term interest rate. The equation also includes an intercept, implying a linear time trend in the corresponding equation for the logarithm of the level of output; this time trend, which represents the "natural" growth rate of supply due to 
growth in productivity and the labor force, is 1.1 percent per quarter. ${ }^{41}$ Given the sample-period means of high-employment federal spending and total gross national product, the estimated spending elasticity implies fiscal-policy multipliers of 0.557 and 1.01 in the short and long runs, respectively. The negative effect of import prices probably reflects the wealth-transfer aspect of a shift in the terms of trade, since the effect of movements in import prices on producers could in general be either positive or negative.

It is worth noting explicitly that the interest rate used in the IS curve here is a nominal yield. In principle, real and nominal yields should both matter independently for real spending. The rationale underlying the role of the real yield is simply the familiar interest elasticity of demand for real product. Some reasons for expecting nominal yields to influence real spending independently of the corresponding real yields include wealth effects associated with nominally denominated government (and foreign) bonds, distribution effects associated with nominally denominated private bonds, nonindexed features of the tax code, the dependence on nominal yields of the effective average life of fixed-payment mortgage contracts, and the effects of legal ceilings on specific nominal yields. Several attempts at approximating an implicit real yield by using simple mechanisms to adjust for price expectations were, however, empirically unsuccessful; ${ }^{42}$ hence the IS curve includes the nominal yield only.

The price-setting equation, II, relates prices to dollar-denominated import prices and the level of output, both lagged one quarter. Since the domestic price index used here is the GNP deflator, which is equivalent to a price index for domestic value added, the effect of import prices here strictly reflects those aspects of competition in "tradables" emphasized in the recent literature; it is therefore a stronger result than the now familiar effect of import prices on indexes, like the consumer price index,

41. Throughout this section, logarithmic differences, multiplied by 100 , are interpreted as quarterly growth rates.

42. In principle, this finding is consistent, on one interpretation, with Fama's argument that the real rate is simply a constant plus a white noise; see Eugene F. Fama, "Short-Term Interest Rates as Predictors of Inflation," American Economic Review, vol. 65 (June 1975), pp. 269-82. It is also consistent, on another interpretation, with the idea that price expectations move sluggishly so as to render movements in real and nominal yields highly correlated in the short run. A more likely explanation is that the expectations mechanisms used (again no lag structure higher than first-order) is just too simple for the purpose, especially given the relatively limited variation of real yields during the sample period. 
for which there is also a direct input effect. Since both the price term and the real-output term in this equation are in logarithmic difference form, this equation is not a conventional "Phillips curve." Comparing the fit and other statistics reveals little empirical basis for choosing between this specification and an alternative in which the rate of change of prices depends on the level of output. ${ }^{43}$

Especially in the context of the a priori restriction to simple specifications and lag structures, the statistical performance of both the IS curve and the price-setting equation individually-and the explanation of movements in nominal income provided by the two together-casts doubt on the familiar assertion that modern macroeconomics has discovered how to explain nominal-income movements but not their separation into real and price components. ${ }^{44}$ The multiple-correlation coefficient of the IS curve is of about the same magnitude typically reported for equations of the St. Louis style explaining arithmetic differences of nominal income, but it is well known that logarithmic differences (which largely eliminate the time trend) are more difficult to explain. The equations recently reported by Michael Hamburger, for example, explaining the logarithmic difference of nominal income using distributed lags on the logarithmic difference of the money stock (as well as two fiscal variables with distributed lags and a strike dummy variable), have $\bar{R}^{2}=0.44$ when the money-stock variable is $\mathrm{M}_{1}$ and only $\bar{R}^{2}=0.35$ when the money-stock variable is $\mathrm{M}_{2} \cdot{ }^{45}$

The $L M$ curve, equation III, relates the demand for real balances (defined as $M_{2}$ ) to real income and the short-term interest rate. ${ }^{46}$ The point

43. The alternative "Phillips curve" result is

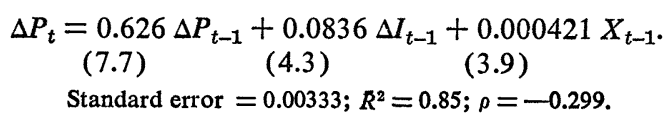

Adding an intercept to II results in a $t$ statistic of 1.4 for the intercept.

44. See, for example, Milton Friedman, "A Monetary Theory of Nominal Income," Journal of Political Economy, vol. 79 (March/April 1971), pp. 323-37.

45. Michael J. Hamburger, "Behavior of the Money Stock: Is There a Puzzle?" Journal of Monetary Economics, vol. 3 (July 1977), p. 286.

46. In part because of the gross failure of standard state-of-the-art equations to track $\mathbf{M}_{1}$ during recent years, many academic economists who are enthusiastic proponents of monetary-growth targets have recently strengthened their consensus that $\mathbf{M}_{2}$ is the right aggregate for this purpose; see, for example, William Fellner and Dan Larkins, "Interpretation of a Regularity in the Behavior of $\mathrm{M}_{2}$," $B P E A, 3: 1976$, pp. 741-61. In light of this growing agreement, however, it is useful to recall that 
estimate of the long-run real-income elasticity of money demand is 1.18 , but it is not possible to reject at the 95 percent confidence level the hypothesis of unit long-run elasticity. Since the short-run elasticities of money demand with respect to real income and prices are sharply different, however, the equation indicates that the anticipated real-price composition of desired growth in nominal income is relevant for selecting the appropriate monetary-growth target. The point estimate of the long-run interest elasticity of money demand is -0.167 .

The money-supply equation, IV, relates the nominal money supply to bank reserves and the short-term interest rate. ${ }^{47}$ The 1.45 point estimate of the long-run elasticity of money supply with respect to reserves is plausible, since time deposits (which bear lower reserve requirements) tend to increase more rapidly than demand deposits. By contrast, the estimated speed of adjustment is surprisingly slow; it is consistent, however, with the familiar notion that the most immediate impact of an open market operation is an offsetting reaction at the discount window. The negative response of money supply to the short-term interest rate is even more surprising - and inconsistent with the conventional assumption as indicated in equation 9. A plausible explanation for this result is that the positive effect of market yields on money supply, associated with banks' incentive to economize on their free reserves, is apparently dominated by the negative effect due to banks' reliance on nonmoney liabilities like negotiable certificates of deposits and Eurodollar borrowings to finance credit expansion.

These explanations for both the low estimated short-run reserves elasticity and the negative estimated interest-rate elasticity of the money supply gain empirical support from an alternative equation using total reserves in place of nonborrowed reserves, which leads to both a larger short-run reserves elasticity and a larger (in absolute value) interest-rate

$\overline{\mathrm{M}_{2} \text {, which includes passbook savings deposits at commercial banks but not at mutual }}$ savings banks or savings and loan associations-and which also includes about half of the large ( $\$ 100,000$ and over) certificates of deposit issued by commercial banks because they are not written to be negotiable-is most difficult to relate sensibly to any theoretical concept in monetary economics.

47. For this one equation only, the results reported above are based on singleequation estimation rather than on Fair's simultaneous-equation procedure. The corresponding results based on Fair's method compound the problem discussed below in connection with the reserves variable. The coefficient estimate for reserves given by Fair's method is 0.0247 with a $t$ statistic of 0.5 . 
elasticity. These differences are as anticipated, since netting out the effect of banks' borrowing at the discount window not only eliminates at least one source of short-run slippage between reserves management and money but also holds constant net free reserves (except for the minor variation in excess reserves). Further support follows from the fact that the same specification of the money-supply equation, estimated using $M_{1}$ instead of $M_{2}$, shows a positive interest-rate effect, as in conventional models. ${ }^{48}$ In addition, an alternative $\mathrm{M}_{2}$-supply equation which includes an intercept term and constrains the long-run reserves elasticity to unity again reproduces the negative interest-rate effect. ${ }^{49}$

The term-structure equation, $\mathrm{V}$, relates the long-term interest rate to the current level and most recent history of the short-term interest rate and to shifts in the maturity composition of outstanding federal debt. Since the equation is in level form, it also includes an intercept, but the estimated value is not significantly different from zero. The point estimate of the long-run elasticity of the long-term interest rate with respect to the short-term interest rate is 1.31 , but it is impossible to reject at the 95 percent confidence level the hypothesis of unit elasticity-which, after deletion of the intercept, implies that the two yields are identical in the long run (apart from any ongoing effects of the debt-management variable). Given the sample-period mean of the long-term interest rate, the 0.0234 logarithmic standard error is equivalent to an absolute standard error of 16 basis points.

For the purposes of short-run analysis, the model is a straightforward five-equation system in five endogenous variables including real income, prices, the money stock, the long-term interest rate, and either the short-term interest rate or the stock of reserves, whichever the Open Market Committee does not select as the exogenous instrument of monetary policy.$^{50}$ In addition, the identity determines nominal income as a sixth endogenous variable.

Although the primary motive behind the construction of this simple

48. The MPS model, which determines both $\mathbf{M}_{1}$ and $\mathbf{M}_{2}$ as endogenous variables, does not show a negative interest-rate effect on $\mathbf{M}_{2}$ because it treats as exogenous the amount of reserves held against time deposits.

49. The finding of a negative interest-rate effect on money supply is independent of the estimation method used. With Fair's simultaneous-equations procedure, the estimated coefficient on the interest rate in IV is -0.0377 with a $t$ statistic of -2.5 .

50. It would, in principle, be possible to close the model completely in this respect by also constructing a sixth equation for the endogenous behavior of monetary policy. 
model is its application to short-run analysis of monetary policy, its implied steady-state growth-equilibrium properties are also of interest. Since equations I-IV are specified in terms of logarithmic differences, while the term-structure equation $\mathrm{V}$ is in logarithmic levels (except for the debt-management variable), in long-run equilibrium the model decomposes into two blocks so that the variables in I-IV are independent of the (nominal) interest rates.

Two alternative long-run interpretations of equations I-IV are possible, corresponding to alternative assumptions about the relevant exchange-rate regime. First, if the Federal Reserve fixes the equilibrium growth rate of reserves, the money-supply equation IV determines the equilibrium growth rate of the nominal money stock which, given the equilibrium growth rate of real output from the IS curve (equation I), determines the equilibrium rate of price inflation via the LM curve (equation III). Then equation II determines the equilibrium rate of change of dollar-denominated import prices which-for fixed real terms of trade, and given the already determined domestic inflation rate-is equivalent to determining the equilibrium appreciation or depreciation of the dollar. Alternatively, if the Federal Reserve fixes the exchange rate, II determines the equilibrium rate of domestic inflation which, again given the equilibrium real growth rate from I, determines the equilibrium rate of monetary growth via III; and now IV determines the equilibrium growth rate of reserves.

A key distinction between the model's short- and long-run implications, therefore, concerns the roles of the exchange rate and of the stock of reserves. In the short run the exchange rate can deviate from strict purchasing-power parity, and the central bank in an open economy can independently control the stock of reserves. By contrast, in the long run the exchange rate must adhere to purchasing-power parity, so that (again given the real terms of trade) the central bank can control independently either the exchange rate or the stock of reserves but not both.

The term-structure equation, $\mathrm{V}$, stands alone in the long run, under either interpretation of equations I-IV. Since it is a separate one-equation system vith two variables, in equilibrium it can merely determine one of the (nominal) interest-rate levels given the other. ${ }^{51}$

51. An additional mechanism, presumably combining the principles of Fisher and Tobin, would be necessary to determine nominal interest rates in long-run equilibrium; see Irving Fisher, The Theory of Interest (Macmillan, 1930), especially chaps. 5 and 19, and James Tobin, "Money and Economic Growth," Econometrica, vol. 33 (October 1965), pp. 671-84. 
PROCESSING THE INFORMATION

IN MONEY-STOCK OBSERVATIONS

How serious is the inefficiency of the intermediate-target procedure associated with its incorrect inference-and-adjustment mechanism for processing the information contained in observations of the money stock? Given the reduced form of the small econometric model developed above, it is straightforward to associate empirical magnitudes with the various concepts in the first two examples of the intermediate-target procedure used above. ${ }^{52}$ In order to abstract from the interesting but complicated issue of how the real-price mix of nominal income influences the appropriate monetary policy, the analysis here takes (the growth rate of) nominal income itself to be the ultimate policy target.

When the information asymmetry that motivates the Open Market Committee to adopt an intermediate-target approach consists of the ability to monitor the money stock but not income on a within-quarter basis, the policy-adjustment mechanism indicated by the intermediate-target procedure is equivalent to using the emerging money surprise $\left(M_{t}-M_{t}^{*}\right)$ to form the key expectation of the reduced-form income residual $\epsilon_{Y t}$, analogously to equation 17 in the IS-LM model, as

$$
E\left(\epsilon_{Y}\right)=\psi^{-1} \theta\left(M_{t}-M_{t}^{*}\right),
$$

where $\psi$ and $\theta$ are again the model's reduced-form coefficients relating the policy instrument to the money stock and nominal income, respectively. By contrast, the correct expression for inferring the expectation of $\epsilon_{Y t}$ on the basis of $\left(M_{t}-M_{t}^{*}\right)$, analogously to equation 18 in the IS-LM model, exploits the true variance-covariance structure of the model's various structural disturbances to identify the covariation of the reduced-form residuals $\epsilon_{Y}$ and $\epsilon_{\hat{M}}$. In other words, while the intermediate-target procedure assumes that all surprises $\left(M_{t}-M_{i}^{*}\right) \neq 0$ are simply reflections of $u_{I S t}$, the correct procedure separates out the likely sources of the compound error $\varepsilon_{M t}$ within the model's estimated variance-covariance matrix. In addition, after determining how much of the money surprise to offset, the correct procedure-unlike the intermediate-target procedure-allows for the interest elasticity of money demand in calculating the offsetting policy action.

52. Since the econometric model does not exhibit the lag structure assumed in equations $1^{\prime}$ and $2^{\prime}$, it cannot be used to analyze the third example based on a structural lag. 
Applying the estimated model's reduced form to this analysis yields the following results: If the monetary-policy instrument is the short-term interest rate, the intermediate-target mechanism yields the inference

$$
E\left(\epsilon_{Y t}\right)=0 \cdot 417\left(M_{t}-M_{t}^{*}\right),
$$

while the correct inference is

$$
E\left(\epsilon_{Y t}\right)=0.711\left(M_{t}-M_{t}^{*}\right) .
$$

If the monetary-policy instrument is reserves, the intermediate-target mechanism again yields the inference

$$
E\left(\epsilon_{Y}\right)=0.417\left(M_{t}-M_{t}^{*}\right),
$$

while the correct inference is

$$
E\left(\epsilon_{Y t}\right)=0.678\left(M_{t}-M_{t}^{*}\right) .
$$

In either case, the inefficiency in the way the intermediate-target approach exploits the information contained in money-stock observations is substantial, leading to a policy response that differs markedly from the correct optimal response. ${ }^{53}$

When the information asymmetry that leads the Open Market Committee to adopt an intermediate-target approach consists instead of the beginning-of-quarter availability of the previous quarter's money-stock value but not the corresponding income value, the policy-adjustment mechanism indicated by the intermediate-target procedure is equivalent to using the observed money surprise $\left(M_{t-1}-M_{t-1}^{*}\right)$ to infer $\epsilon_{Y t}$, analogously to equation 20 in the IS-LM model, as

$$
E\left(\epsilon_{Y t}\right)=\psi^{-1} \theta \rho_{M}\left(M_{t-1}-M_{t-1}^{*}\right),
$$

where $\rho_{M}$ is again the indirect serial-correlation coefficient of $\varepsilon_{M}$. By contrast, the correct expression for inferring the expectation of $\varepsilon_{Y t}$ on the basis of $\left(M_{t-1}-M_{t-1}^{*}\right)$, analogously to equation 21 in the IS-LM model, again exploits the true underlying variance-covariance structure.

53. For the model estimated with the interest rate treated as exogenous, the four numbers reported in the text are, respectively, $0.346,0.655,0.346$, and 0.564 . The apparently counterintuitive result that the intermediate-target procedure leads monetary policy to underestimate the income disturbance-that is, to undershoot the correct interest-rate adjustment-is due to the effect of $b_{2} \neq 0$ in equation 17 dominating the effect of $\sigma_{L M}^{2} \neq 0$ in equation 18 . Given the negative interest elasticity of money demand, the interest-rate adjustment that merely returns $M$ to the original $M^{*}$ is not sufficient to return $Y$ to $Y^{*}$; instead, it is necessary for $M$ to overshoot $M^{*}$. 
Applying the estimated model's reduced form to this analysis yields the following results: If the monetary-policy instrument is the short-term interest rate, the intermediate-target mechanism yields the inference

$$
E\left(\epsilon_{Y t}\right)=0.0197\left(M_{t-1}-M_{t-1}^{*}\right),
$$

while the correct inference is

$$
E\left(\epsilon_{Y t}\right)=0.266\left(M_{t-1}-M_{t-1}^{*}\right) .
$$

If the monetary-policy instrument is reserves, the intermediate-target mechanism yields the inference

$$
E\left(\epsilon_{Y t}\right)=-0.00561\left(M_{t-1}-M_{t-1}^{*}\right),
$$

while the correct inference is

$$
E\left(\epsilon_{Y t}\right)=0.246\left(M_{t-1}-M_{t-1}^{*}\right) .
$$

In either case, the small serial correlation in the $\left(M-M^{*}\right)$ series leads the intermediate-target procedure to yield a negligible (and, when the instrument is reserves, even perverse) policy response, in contrast to the substantial response indicated by the correct exploitation of the information contained in the observation of the previous quarter's money stock. ${ }^{54}$

Given the limitations of the underlying macroeconometric model, the failure of the monetary-target approach to perform well in these simple tests clearly does not provide the last word on the subject. Nevertheless, these tests are instructive, at the very least in that they demonstrate the need for analysis of the intermediate-target procedure based on more sophisticated models. ${ }^{55}$ On the basis of these tests alone, the inefficiency of the intermediate-target procedure based on the money stock as the intermediate target variable appears to be substantial.

\section{A DIGRESSION ON STRATEGY AND TACTICS}

The earlier discussion of the theory underlying the strategy and tactics of monetary policy shows for the IS-LM model that the Open Market

54. For the model estimated with the interest rate treated as exogenous, the four numbers reported in the text are, respectively, 0.0412, $0.323,0.0145$, and 0.278 .

55. In addition, it would be useful to generalize the analysis by relaxing the assumption that the exogenous variables and the model's coefficients are known with certainty; see William Brainard, "Uncertainty and the Effectiveness of Policy," American Economic Review, vol. 57 (May 1967), pp. 411-25. 
Committee's choice between a directly implementable strategy based on the short-term interest rate and the alternative based on the money stock -which requires some tactics for monetary control-depends on the comparison of $\sigma_{Y \mid r}^{2}$ in equation 6 and $\sigma_{Y \mid M}^{2}$ in equation 8. The model presented above, which is an expanded IS-LM structure, is also interesting for its implications for the gross orders of magnitude involved in monetary policy apart from the intermediate-target approach per se.

First, at the strategy level, the comparison indicated by the model (expressed, for ease of interpretation, as standard deviations rather than variances $)^{56}$ is

$$
\sigma_{Y \mid r_{s}}=0.852 \%
$$

versus

$$
\sigma_{Y \mid M}=0.788 \% \text {. }
$$

Given the U.S. nominal gross national product in 1976, these two standard deviations in the quarterly growth rates correspond to dollar magnitudes of $\$ 14.5$ billion versus $\$ 13.4$ billion at annual rates. Hence the model does imply an advantage — albeit an extremely small one-for use of the money stock at the strategy level. ${ }^{57}$

A well-known contradiction inherent in the two-stage strategy-andtactics approach, however, concerns the controllability of the money stock..$^{58}$ In particular, the very existence of the tactics stage of the analysis contradicts a key assumption made at the strategy stage, since the expected squared deviations in equations 6 and 8 are valid only under the assumption that it is indeed possible to set $r$ precisely equal to $r^{*}$ and $M$ to $M^{*}$. If the interest rate and the money stock are instead variables with expectation $E(r)=r^{*}$ and $E(M)=M^{*}$ but with nonzero variances

56. Throughout the following discussion, all estimated standard deviations for $\Delta Y$ and $\Delta M$ are multiplied by 100 to permit interpretation in terms of percentage growth rates. The values used in the underlying calculations are the variances and covariances of the white noises rather than the disturbances themselves, so that the analysis here assumes the ability of policy to take full advantage of past observations; equivalent calculations based on the disturbances show no interesting differences.

57. For the model estimated wtih the interest rate treated as exogenous, the corresponding standard deviations are $\sigma_{Y \mid r_{S}}=0.816 \%$ and $\sigma_{Y \mid M}=0.772 \%$.

58. See, for example, Friedman, "Targets, Instruments, and Indicators"; Poole and Lieberman, "Improving Monetary Control"; and Pierce and Thomson, "Some Issues in Controlling the Stock of Money." 
$\sigma_{r}^{2}$ and $\sigma_{M}^{2}$, then the correct expressions for $\sigma_{Y}^{2}$ are different from-specifically, larger than-equations 6 and 8 .

Since the $r_{S}$ variable used here is a nominal short-term yield, it is reasonable to suppose that in the short run the Open Market Committee can set this variable as a true instrument, so that $\sigma_{r_{S}}^{2}=0$ and the value shown above for $\sigma_{Y \mid r_{s}}$ is correct. By contrast, the fundamental motivation for the tactics stage of the analysis-as well as the intermediate-target procedure - arises because surprises occur in the endogenous variable $M$ as well as in $Y$. Apart from the covariance between $\epsilon_{Y}$ and $\epsilon_{M}$, therefore, the $\sigma_{Y \mid M}^{2}$ value corresponding to $\sigma_{Y \mid M}$ is too small in that it omits a term equal to the relevant $\sigma_{M}^{2}$ multiplied by a coefficient equivalent to the square of $\phi$ in equation 4.

How serious is the omission, at the strategy stage of the analysis, of the noncontrollability of the money stock? It is, of course, possible that, even if the relevant variances, covariances, and slope coefficients suggest that the money stock is a better focus of monetary policy than are interest rates, the interest-rate strategy may be superior after all, given the achievable precision of control over the money stock. Is this in fact the case?

For several reasons it is difficult to evaluate the degree of achievable monetary control. First, as William Poole and Charles Lieberman have shown, many of the barriers to close monetary control are institutional arrangements that in principle could be changed if the Federal Reserve and the Congress considered monetary control sufficiently important. ${ }^{59}$ Second, even under current arrangements, the Open Market Committee's short-run objective of preserving stability in the money market (that is, in interest rates) precludes interpreting the observed degree of monetary control as the feasible maximum. Third, the fluid state of both banking arrangements and estimated equations for money demand and supply obscures the degree to which previous empirical work on this question is relevant-especially for $\mathrm{M}_{2}$.

The econometric model presented above, however, can provide an upper bound on the $\sigma_{M L}^{2}$ measure in question-but only on the implausible assumption that income is known. For given real output and prices, solving out the model's LM curve and money-supply equation yields the value

$$
\sigma_{M \mid r s}=0.601 \%
$$

59. Poole and Lieberman, "Improving Monetary Control." 
when the policy instrument is the short-term interest rate versus

$$
\sigma_{M \mid R}=0.926 \%
$$

when the policy instrument is reserves. Given the level of $\mathrm{M}_{2}$ for December 1976, these two standard deviations in the quarterly growth rates correspond to dollar magnitudes of $\$ 4.4$ billion versus $\$ 6.8$ billion.

If these results truly reflected the feasible precision of control over $\mathrm{M}_{2}$, they would in the first instance indicate that at the tactics level the interest rate is a better choice than reserves as the instrument of monetary policy. In addition, allowing for the estimated imprecision of monetary control changes the estimate of $\sigma_{Y \mid M}$ from the value shown above to

$$
\sigma_{Y|(M)| r_{s}}=0.827 \%
$$

when the instrument is the interest rate and

$$
\sigma_{Y|(M)| R}=0.846 \%
$$

when the instrument is reserves. Since the implications for income of imprecise monetary control are apparently small, as measured via the model's reduced form, in neither case does allowing for imperfect monetary control at the tactics stage overturn the initial conclusion favoring the money stock at the strategy stage-although in both cases it makes an already thin margin even thinner.

Nevertheless, since the $\sigma_{M \mid r_{s}}$ and $\sigma_{M \mid R}$ values derived from the quarterly econometric model do not allow for within-quarter monitoring of the money stock and consequent adjustment of the policy instrument, they provide in this sense only a pair of upper bounds that (along with a zero lower bound) bracket the true values of achievable monetary control. A monthly or weekly model, which lies beyond the scope of this paper, is necessary to refine these estimates.

Finally, how about simply setting the stock of reserves so as to influence income, and ignoring the money stock? Here the estimated model indicates the value ${ }^{60}$

$$
\sigma_{Y \mid R}=0.827 \% \text {. }
$$

In sum, a comparison of all of the $\sigma_{Y}$ values shown here indicates that, at least on the basis of the simple econometric model presented above, there

60. The fact that $\sigma_{Y \mid R}$ and $\sigma_{Y|(M)|_{B}}$ are both reported as 0.827 percent is due to rounding; the two measures are in general not equal. 
is little empirical ground for arguing the superiority of one short-run monetary policy instrument over another.

\section{Conclusions for Monetary Policy}

At the conceptual level this paper offers two basic criticisms of the current monetary-policy strategy based on the money stock as an intermediate-target variable.

First, the intermediate-target procedure based on monetary targets is a useful but in general an inefficient way of exploiting the information contained in near-term observations of the money stock. Except under the highly restrictive conditions that the demand for money is both interest insensitive and perfectly stable (neither of which receives support from the empirical investigations in this paper or elsewhere), the intermediate-target procedure is in general inferior to an alternative, more general, procedure for adjusting policy in light of the relevant information contained in observed money-stock values.

Second, the intermediate-target procedure based on monetary targets suffers from the further-and potentially more damaging-shortcoming of hindering monetary policy from exploiting the near-term flow of information contained in observations of variables other than the money stock. With information as scarce as it is, any that nonmonetary sources offer should be exploited; and the use of the intermediate-target procedure, in contrast to a more general "information variable" procedure, leads to a mistaken strategy of exploiting only those variables that are not only observable but also largely "controllable" in the short run.

At the empirical level the paper provides some limited evaluation of the first of these criticisms. Results based on a compact, analytically tractable macroeconometric model estimated particularly for this application indicate that the intermediate-target procedure based on monetary targets exploits the information in money-stock observations with substantial inefficiency. This procedure, which involves responding to observed deviations of the money stock from the targeted growth path so as to restore money to that path, calls for a monetary-policy response that differs markedly from that which a correct processing of the information contained in the observed deviations would warrant-regardless of whether the instrument of monetary policy is a short-term interest rate or bank reserves. 
The basic implication of these analytical and empirical results is that the Federal Open Market Committee should not seek to control the money stock as an intermediate target of monetary policy. Even if on a near-term basis the committee were to focus only on the money stock, its response to observed movements should still be different from that indicated by the intermediate-target strategy. Perhaps more important, the committee should focus not just on the money stock but rather, at the very least, on an index of monetary and credit aggregates. In addition, the committee should seek better ways of incorporating into its analysis the near-term flow of information from financial variables other than financial aggregates, and from nonfinancial sources too. The fundamental point is not that near-term observations of the money stock contain no useful information for monetary policy but only that they do not contain all such useful information. While money should not be the intermediatetarget variable of monetary policy, therefore, it should be a useful and probably an important information variable-but not the only one.

Whether these conclusions constitute criticism or praise of the current short-run conduct of U.S. monetary policy is an empirical question on which this paper draws no judgment. To the extent that the Federal Open Market Committee does attempt within the short run to control the money stock closely about a predetermined growth target, this analysis indicates the direction in which to change current operating procedures. Alternatively, to the extent that the committee already pursues systematically a more flexible and comprehensive short-run operating procedure, this analysis suggests that it continue to resist the frequent urging to narrow its focus onto short-run control of the money stock. In either case, the implications for future monetary policy are clear. 


\section{Comments and Discussion}

James Duesenberry: I shall attempt to develop the central logic of Friedman's paper and also to dwell on some aspects of that logic that deserve more emphasis, in my judgment, than they received in the paper.

A good starting proposition is that an unexpected change in the money supply raises a question: What does it tell us and what should be done about it? To put it more formally, the Open Market Committee begins with a consistent forecast of the money supply, reserves, interest rates, and income, taking account of relationships that link these variables. In light of where they would like income to move in the short run, they set either a rate for federal funds or a level of reserves with the expectation that the influence of that decision on the money supply will, in turn, influence income appropriately. Suppose they develop this forecast on a quarterly basis; and then suppose that, after the first month of the quarter (say, April for the spring quarter), they get information that the money supply is not where they expected it to be. At that point, they do not have information about the level of income during April.

The deviation in the money supply for April could, in principle, represent any one of a number of things: a shift in the LM function; an error in the prediction of one of the exogenous variables that enter into that function; or a deviation of income from its expected value that changed the demand for money. Or it could be a mere measurement error. Now the question is, what information is available that can help the Federal Reserve track down the source of the observed deviation in the money supply from its expected value?

One category of such information relates to financial flows. In attempting to diagnose events in the latest month, one should be hunting for the best current short-term indicator, which is not necessarily the best leading 
indicator. More significantly, one would have to relate any new financial information back to the initial prediction. For example, suppose that the data on commercial loans for April show a big, unexpected rise, and that there is general empirical evidence that commercial loans rise contemporaneously with inventory investment. If the initial forecast had called for only a modest rate of inventory investment, the surge in commercial loans might suggest that inventory investment had been unexpectedly strong and had raised income above its anticipated level, thereby contributing to the bulge in the money supply. But that is information only because the observed rise in commercial loans is inconsistent with the prediction of inventory change. If a high rate of inventory investment had been expected, the big rise in commercial loans would not serve as a clue.

The information value of any new data to the Federal Reserve thus depends on the underlying forecast that led the Federal Reserve to pick the actual money target. If, in fact, the Fed did not base that target on any particular consistent and detailed forecast, then there is no way for them (or anybody else) to calibrate the flow of new information.

In addition to the financial indicators, a large variety of nonfinancial information may help to track down the source of a surprise in the money supply. During April, the Federal Reserve will have received scraps of information about automobile sales, weekly retail sales, and the like. Even if no information is available about activity during the month of April as a whole, monthly reports on March will have come in, supplying information that was not available at the beginning of the quarter. The policymakers know a lot more about March economic activity on May 1 than they knew on April 1. And that information may help them to judge whether the level of economic activity during April was higher than they had anticipated initially. This is all part of the process of digesting and interpreting information that Friedman describes.

The paper next goes into a detailed discussion of the adjustments in policy the Federal Reserve might make once it has diagnosed the source of the money surprise. The right adjustment obviously depends on the size of the error and the confidence in the diagnosis, but it also depends on the estimated responses of the system to any adjustments in policy that might be made.

Given the way the system responds, in fact, any action taken by the Federal Reserve will not have much effect in the current quarter. Moreover, any attempt to manipulate income month by month, or even quarter 
by quarter, might jostle the money supply and interest rates around in wide ranges that may impose some costs in themselves. Hence, the monetary-policy decision has to be made in a somewhat longer-term context, looking at least another quarter (if not several quarters) ahead. That longer look must be taken with extreme care in assessing the genuine information content of any indicators that may be used to diagnose shortterm deviations in the money supply. It also must face the issue of serial correlation. Friedman has an especially interesting discussion of the role of serial-correlation coefficients in consecutive quarters. In some cases, if the federal funds rate (or the path of reserves) is unchanged, the money supply will come back to its target track. But if that is not a reasonable prediction, the Federal Reserve must decide whether to work down the bulge in the money supply by tightening its instruments (as it should for an IS disturbance) or to leave its funds-rate (or reserves) instrument unchanged and accept the higher money supply (as it should for an LM disturbance).

All of these issues are developed in the paper in a way that seems perfectly reasonable and illuminating to me. Perhaps the only new point that I am emphasizing is the importance of the Federal Reserve's initial forecast as a benchmark for interpreting new information. But I have more serious reservations about the small econometric model that Friedman introduces to illustrate this process concretely. A number of the elements in the model seem rather peculiar to me, and some of these are the result of its compression. In general, I could not have much faith in a model that is so small (although I am not sure that I could have much more faith in a larger model). I do not feel that the model helps to guide us empirically on what ought to be done in the face of an unexpected deviation in the money supply. Indeed, any model concentrates on additive error terms, and that may distract attention from the real uncertainty in policy-the wide variations in plausible values of the parameters of the system.

Finally, Friedman's model continues to focus on the extremely short run. The horizon should be lengthened. Once it is, the big new question is, how does one judge whether to make an adjustment in monetary policy early on the basis of feeble information or to delay it in hope of better information? Suppose that, in my initial example, there is some basis for concluding on May 1 that the bulge in the money supply should be eliminated, but also a recognition that, by June 1 or July 1, much more reli- 
able information will be available on the actual course of income during the quarter. The lead time in taking corrective action is obviously valuable, but so is the fuller information. My own off-the-cuff inclination is toward waiting a bit longer to see what happens. Such issues should be explored in future work; they have been neglected, compared with extremely short-run adjustments. Designing a somewhat longer-run strategy in the face of inadequate information about the structure of the system seems to me the really difficult challenge. Friedman leaves that problem unsolved; but he has defined more sharply than ever before the issues concerning relevant information and rational response by the Federal Reserve to information and surprises. Hence, the paper has served a very useful purpose.

William Poole: I shall begin by interpreting Friedman's approach to monetary policymaking within the structure of the optimum control model. Initially, suppose that the money stock, income, and the interest rate are all observed continuously. In that case, we know that, in general, neither a monetary instrument nor an interest-rate instrument would be optimal. The ideal policy would be a combination policy that permits both money supply and interest rates to change in response to disturbances.

Taking the next step to reach the framework within which Friedman conducts his analysis, suppose that interest rates are observed continuously, but that the money stock is known only with a one-month lag and income with a one-quarter lag. Then the combination policy cannot be followed because it is impossible to maintain a known fixed relationship between money and interest rates. As Friedman suggests, one feasible alternative involves controlling the federal funds rate and changing that rate in response to the monthly observations of the money stock. In implementing such a policy, it is obviously not optimal to maintain the original money target regardless of anything else that is learned about the economy.

Friedman makes the point in the following way. If the Federal Reserve sticks to its initial monetary target when it observes a bulge in the money stock, then it must raise the federal funds rate by whatever amount it estimates to be necessary to bring the money stock back down to its target path. The required rise in the interest rate will reflect the estimated reduction in money demand associated with (1) an increase in the interest rate, and (2) the reduction in income brought about by the higher inter- 
est rate. The strategy of bringing the money stock back to target involves processing the data, using certain key parameters-the income and interest elasticities of money demand and the coefficient of the interest rate in the IS function. These parameters will permit a calculation of the size of the required change in the interest rate.

The difference between the original interest-rate setting and the new, revised one is calculated as though the deviation in the money stock was caused entirely by an IS disturbance. Friedman argues that this estimate will in general not be correct because it ignores the possibility of disturbances stemming from the money-demand function. Friedman then derives the optimal inference that attributes money-growth surprises to some combination of money-demand disturbances and IS disturbances.

It turns out, however, that, in the model Friedman estimated for illustrative purposes, the optimal inference involves a larger adjustment of interest rates than would be made in the strategy that attributes the deviation entirely to an IS disturbance. This interesting result is strikingly counterintuitive. One would think that, when any observed surprise in the money stock is attributed to money-demand disturbances as well as IS disturbances, part of the deviation of money from its expected path would be discounted. In effect, Friedman is suggesting that monetary policy would not react enough to deviations in money if it followed the strategy of sticking to the initial money target and ignored the information contained in the monetary deviation.

My concern, however, is that Friedman's characterization of the intermediate-target process suffers from its concentration on the two-equation IS-LM model. In my view, the motivation for the intermediate-target approach is really quite different. It rests on the view that there is a moneysupply function operating and that an unexpected deviation in the money stock is interpreted primarily, not as a reflection of an IS disturbance, but rather as a money-supply disturbance. The reason to reverse the moneysupply disturbance is precisely to keep it from feeding into income.

To understand what $I$ have in mind, consider the microeconomic stochastic money-demand models in which money balances may fluctuate between upper and lower bounds before inducing action. For example, a firm's balances may fluctuate stochastically as a result of accidents of timing of receipts and payments. If the cash balance gets large (small) enough then Treasury bills may be purchased (sold), but not every $\$ 100$ fluctuation in the cash balance leads to such action. Thus, a money-supply 
disturbance-whether resulting from a disturbance within the commercial banking system (such as a change in holdings of excess reserves) or resulting from a disturbance induced by, or not offset by, the central bank (such as a change in float) - can affect the amount of money held without initially feeding back on any of the arguments of a conventional aggregate money-demand function.

In the context of an aggregate money-demand function, then, a supply disturbance may simply show up in the error term of the demand function. The important distinction here is that the error appears because of a supply disturbance and not because of a shift in the deterministic part of the money-demand function. If the deterministic part of the demand function remains unchanged, then the money-supply disturbance will eventually lead to changes in the arguments of the money-demand function as holders of money react to a supply of money that is excessive or deficient at the initial levels of income and interest.

On this view, the case for an intermediate monetary target reflects the desire to prevent money-supply disturbances from existing long enough to feed into income. In the context of Friedman's model, when the money stock is observed after the fact to have been higher or lower than expected, given the pegged federal funds rate, the inference problem involves sorting out money-supply disturbances as well as IS and money-demand disturbances. Abstracting from the very real data problems, my guess is that the vast bulk of weekly and monthly money-growth surprises reflect money-supply disturbances rather than either IS or money-demand disturbances.

Next, I have a few comments on Friedman's characterization of the making of Federal Reserve policy. The paper gives the impression that the Federal Reserve has really stuck quite religiously to a monetary target and has adjusted interest rates actively in pursuit of this target, ignoring other relevant information. My impression of the situation is rather the reverse-that the Federal Reserve responds to an enormous amount of information, some of which may be valuable and some of which may be useless or even misleading. At each monthly meeting the Federal Open Market Committee is in fact presented with an enormous briefing book with masses of information. Moreover, I do not find that the federal funds rate has been moved around aggressively in hot pursuit of the money target path. Instead, the stated monetary target for the near term is consistently changed in order to reflect forecasts of the money stock under a rela- 
tively unchanged setting of the federal funds rate. As further evidence that little attention has been paid to short-run monetary control, I am impressed that the Federal Reserve has not undertaken institutional reforms that would enable it to control the money stock more accurately. Indeed, the Fed has taken steps such as the introduction of additional reserve categories with differing required reserve ratios that make it harder to control money.

The illustrative empirical results in the paper, as I interpret them, suggest that it is pretty much of a draw whether the Federal Reserve pursues interest-rate targets or money-stock targets. I think that result is probably correct, in fact. As I see it, the real issue is not so much whether the Federal Reserve controls the money stock or the interest rate in the short run but whether the instrument, whichever it is, is adjusted promptly and decisively in the appropriate direction. Problems arise because when the policymakers set an interest-rate target they put themselves into a position in which, for reasons mentioned below, they tend to keep that instrument setting unchanged.

Thus, in practice, the real difference in policy effectiveness arising from the choice of instrument arises out of a tendency toward sluggish committee decisionmaking. If a consensus cannot be reached on action, the FOMC stands pat. The committee is sensitive to political pressures to avoid policy reversals and hence is reluctant to push the instrument in one direction one month and then to reverse it the next. The political pressures to hold down interest rates make it difficult not only to raise them but also to push them down when that is appropriate: if the Federal Reserve thinks it will have to reverse such a policy subsequently, it expects more criticism from the rate movement back up than approval on the way down. Once an interest-rate target has been picked, the great tendency is simply to hold onto it. Substitution of a short-run reserves target for the federal funds target would not make committee decisionmaking less sluggish but would improve monetary policy because it is so much less costly to be sluggish over reserves than over interest rates.

Finally, let me raise the issue of rational expectations. Abstracting from the most austere version of that argument, which destroys any possibility of constructive stabilization policy, I would argue that at least some behavioral relationships of the private sector will look different in the macroeconomic model if the government authorities follow one policy regime rather than another. That is simply a matter of recognizing that 
private decisionmakers take the character of government policy into account. Thus, the choice of policy strategy has to make some difference to macro model equations as usually formulated; that in itself upsets the basic assumption of the optimal-control model that the implications of different policy strategies can be explored within a given structure of private behavior. Ideally, one needs to know the structural model of behavior with money-stock targets and that with interest-rate targets in order to determine which policy regime leads to a more stable economy. This consideration leads me to have serious reservations about the optimalcontrol approach. We have to be extremely careful in drawing lessons from that approach, recognizing that it takes no account of rational expectations.

\section{General Discussion}

Frederic Mishkin underlined the importance of uncertainty about the structure of economic relationships and their parameter values-a problem that, as Duesenberry had noted, was not covered by Friedman. He thought that money-supply targets might be defended as a second-best way of reducing the variance of one factor in a system that was permeated with uncertainty about its structure and its parameter values.

William Fellner felt that the critical choice was not simply between formalizing some relationships and ignoring others. Policymakers might take some information into account in an intuitive or ad hoc fashion and yet be reluctant to model this linkage explicitly, in view of the uncertainties about structure and parameter values.

Ralph Bryant wanted to focus attention on the two-stage decisionmaking process in the intermediate-target approach. At an "upper level," policymakers decide what money stock is consistent with ultimate targets, such as income and the price level; then, at a "lower level," decisions aim to manipulate the instruments to make the money stock grow along that path. He summarized the various rationales that might be given for such a two-stage approach and noted that none was convincing. In particular, as Friedman's paper helped to show, however uncertain policymakers were about the model of the economy and whatever the characteristics of the information available to them at particular points in time, they could always do better by looking at several variables than by putting all their eggs in the basket of one particular intermediate-target variable. 
Bryant was also not convinced by the argument that the use of intermediate targets was the best way to help private decisionmakers form their expectations. Intermediate variables such as the money stock cannot be controlled precisely nor are they an ultimate objective. Policymakers could better inform private decisionmakers by announcing their intentions with respect to their ultimate objectives or the instruments that they could actually control, or both.

Arthur Okun felt that the case for splitting the decisionmaking process into two parts had to rest on the assumptions (1) that what really drives the economy is the monetary aggregate; and (2) that the problem of keeping the monetary aggregate on track is best handled by delegating it to a group of experts. Then it could be best to fix the aggregate target with no discretion and give the experts who have a feel for the market the discretion to achieve that target as best they can. Bryant and Okun agreed that this implied an asymmetrical use of information: the data helpful in keeping money on target would have to have no value in pointing toward the need for a revision of the target.

William Poole pointed out that it was possible to get a continuous feedback on the money supply, but that observations on economic activity came infrequently, with lags that prevented effective control. In the former case, one could, in effect, use the steering wheel to stay on the road; in the latter, one could not.

Edward Gramlich reminded Friedman that another important type of information neglected in money-supply targeting was that relating to exogenous movements in prices-grains, oil, imports in general. A change in such prices would call for a revision of the money-supply target.

Participants differed in their interpretations of recent Federal Reserve actions. Robert Solomon felt that the Fed had given primacy to $M_{1}$ targets during the spring and summer of 1977. In spite of a weakening of economic indicators, they had pushed interest rates up sharply in response to an acceleration of $\mathbf{M}_{1}$. William Poole countered that neither the current level nor the recent movements of interest rates suggested that the Federal Reserve had worked very hard to keep the aggregates on target. Moreover, he had seen little evidence of the reduction in the variability of money growth over time that should occur if a policy focusing on monetary aggregates was being diligently pursued. Okun suspected that the inertia of committee decisionmaking that Poole had mentioned now ap- 
plied to the choice of monetary targets whereas formerly it had applied to interest rates. He felt that compelling evidence pointed to the need for an upward revision in the $\mathrm{M}_{1}$ target in light of the unexpected slowdown of velocity, but that the Open Market Committee found it difficult to alter the target because they would be admitting implicitly that they had made a mistake. Duesenberry noted that the behavior of $M_{1}$ in 1977 led one to suspect that it might be returning to a more normal historical marginal relationship with the growth of nominal GNP. If that was indeed the case and the Federal Reserve did not adjust, monetary policy would be on a collision course with the economic expansion. Solomon reminded the group that Chairman Burns had indicated his willingness to change targets if significant deviations in velocity developed.

Friedman cited the discussion as evidence of the difficulty in reaching a consensus on what the Fed is actually doing. Recognizing that difficulty, he had tried to be agnostic on this question in his paper. He did cite the finding of one study that the federal funds rate was increasingly influenced by money growth during the seventies. In addition, he noted the behavior of the Open Market Committee in sharply raising short-term interest rates during the summer after $\mathbf{M}_{1}$ had spurted while virtually no other available evidence suggested excessive economic strength. In fact, he observed, most of the debate over the economic outlook lately had been over whether or not the economy would experience a growth recession in 1978. Friedman found it amusing that everyone tends to think that the Fed does what he personally thinks they ought not to do. Those who espouse monetary targets feel that policy pays little attention to them; those who favor an eclectic indicators approach feel that the money supply looms large in policymaking.

In response to Poole's comments, Friedman noted that his analysis did encompass money-supply behavior. For simplicity, his exposition had relied on the two-equation IS-LM model. The analytical principles he was emphasizing extended in a straightforward way to include moneysupply behavior, however, and the money supply was explicitly endogenous in his empirical work.

Responding to another issue raised in the discussion, Friedman expressed his own uncertainties about the optimum size of econometric models for the purpose of guiding policy. He reiterated that his model was meant to be illustrative; yet he felt that compact models of that sort might 
be an appropriate middle ground between cumbersome, complex, largescale models and the single equation that encompassed only income and the money stock.

Finally, Friedman was puzzled by the tendency of some economists to view single-minded control of the money stock as a fallback position justified by gross uncertainty about how the economy works. The risk of major error is reduced thereby only if the money-stock relationships are reliable. To advocate close money-stock control, therefore, also presumes knowledge about economic behavior. In fact, the recent behavior of $\mathbf{M}_{1}$ has been unstable; and the more stable behavior of $\mathrm{M}_{2}$ cannot be relied on to continue indefinitely. 